\title{
Effect of Dip-Coating Cycle on Some Physical Properties of Cu2NiSnS4 Thin Films for Photovoltaic Applications
}

\section{Ahmed ZITI ( $\square$ ziti.ahmed91@gmail.com )}

FSTM: Universite Hassan II Casablanca Faculte des Sciences Techniques Mohammedia https://orcid.org/0000-0002-0995-4527

\section{Bouchaib HARTITI}

FSTM: Universite Hassan II Casablanca Faculte des Sciences Techniques Mohammedia

\section{Amine BELAFHAILI}

Mohammed V Agdal University: Universite Mohammed V de Rabat

\section{Hicham LABRIM}

CNESTEN Rabat

\section{Salah FADILI}

FSTM: Universite Hassan II Casablanca Faculte des Sciences Techniques Mohammedia

\section{Abderraouf RIDAH}

Hassan II University: Universite Hassan II Casablanca

\section{Mounia TAHRI}

CNESTEN Rabat

\section{Philippe THEVENIN}

University of Lorraine: Universite de Lorraine

\section{Original Research}

Keywords: CNTS, sol-gel, dip-coating cycle, cubic, band gap.

Posted Date: February 16th, 2021

DOI: https://doi.org/10.21203/rs.3.rs-194196/v1

License: (c) (i) This work is licensed under a Creative Commons Attribution 4.0 International License. Read Full License 


\title{
Effect of dip-coating cycle on some physical properties of $\mathrm{Cu}_{2} \mathrm{NiSnS}_{4}$ thin films for photovoltaic applications
}

\author{
Ahmed ZITI $^{{ }^{*}}$, Bouchaib HARTITI ${ }^{1}$, Amine BELAFHAILI ${ }^{4}$, Hicham LABRIM ${ }^{3}$, \\ Salah FADILI ${ }^{1}$, Abderraouf RIDAH ${ }^{2}$, Mounia TAHRI ${ }^{3}$, Philippe THEVENIN ${ }^{5}$ \\ ${ }^{1}$ ERDyS laboratory, MEEM \& DD Group, Hassan II University of Casablanca, FSTM BP \\ 146 Mohammedia 20650, Morocco. \\ ${ }^{2}$ LIMAT laboratory, Department of Physics FSB, Hassan II University of Casablanca \\ ${ }^{3}$ DERS, CNESTEN, Rabat, Morocco \\ ${ }^{4}$ Centre for Electron Microscopy, Faculty of Sciences, Mohammed V University, \\ Rabat, Morocco \\ ${ }^{5}$ University of Lorraine, LMOPS, METZ, France \\ * Email: ziti.ahmed91@ gmail.com
}

Abstract

Quaternary semiconductor $\mathrm{Cu}_{2} \mathrm{NiSnS}_{4}$ thin film was made by the sol-gel method associated to dip-coating technique on ordinary glass substrates. In this paper, we have studied the impact of dip-coating cycle at different cycles: 4, 5 and 6 on the structural, compositional, morphological, optical and electrical characteristics. CNTS thin films have been analyzed by various characterization techniques including: X-ray diffractometer (XRD), Raman measurements, scanning electron microscope (SEM), energy dispersive X-ray spectroscope (EDS), UV-visible spectroscopy and four-point probe method. XRD spectra demonstrated the formation of cubic $\mathrm{Cu}_{2} \mathrm{NiSnS}_{4}$ with privileged orientation at (111) plane. Crystallite size of cubic CNTS thin films increase with from 6.30 to 9.52 with dip-coating cycle augmented. Raman scattering confirmed the existence of CNTS thin films by Raman vibrational mode positioned at $332 \mathrm{~cm}^{-1}$. EDS investigations showed near-stoichiometry of CNTS sample deposited at 5 cycles. Scanning electron microscope showed uniform surface morphologies without any crack. UV-visible spectroscopy indicated that the optical absorption values are larger than $10^{4} \mathrm{~cm}^{-1}$, Estimated band gap energy of CNTS absorber layers decrease from 1.64 to $1.5 \mathrm{eV}$ with dip-coating cycle increased. The electrical conductivity of CNTS thin films increase from 0.19 to $4.16(\Omega . \mathrm{cm})^{-1}$. These characteristics are suitable for solar cells applications.

Keywords: CNTS, sol-gel, dip-coating cycle, cubic, band gap. 


\section{Introduction}

The costly and scarcity of galium (Ga) and indium (In) and toxicity of cadmium (Cd) limited the future of high efficient copper indium gallium sulphur $\mathrm{Cu}_{2} \mathrm{InGaS}_{2}$ and cadmium telluride CdTe absorbers materials [1,2]. Due to these problems, the quaternary semiconductor $\mathrm{Cu}_{2} \mathrm{ZnSnS}_{4}$ (CZTS) is emerged as interest and appropriate absorber layer in photovoltaic solar cell based thin films during several years; CZTS thin film is low cost and abundant in earth crust [3-5]. The power conversion efficiency of $12.6 \%$, but this efficiency does not improved from 2014 until this year [6]. In addition $\mathrm{Cu}_{2} \mathrm{ZnSnS}_{4}$ has a wider range of possible defects depending on its growing conditions and variations in stoichiometry, most of the anti-sites $\mathrm{Cu}_{\mathrm{Zn}}, \mathrm{Sn}_{\mathrm{Zn}}$, and $\mathrm{Zn}_{\mathrm{Sn}}$ ) [7], theses defect influence negatively on the efficiency of CZTS solar cells. Effectively, the studies of semiconductors absorbers are separated in two major axes: Firstly the improve of CZTS thin film in solar cell for photovoltaic application [8], and secondly the amelioration of solar cell performances using a novel approach that has entice serious intension in 2020 from some research investigations is the substitution $\mathrm{Zn}^{2+}$ by other elements has similar valence electronic including: $\mathrm{Mn}^{2+}, \mathrm{Mg}^{2+}, \mathrm{Fe}^{2+}, \mathrm{Co}^{2+}, \mathrm{Ba}^{2+}, \mathrm{Ni}^{2+}$ these research lead to develop the novel low cost semiconductors absorbers layers $\mathrm{Cu}_{2} \mathrm{MnSnS}_{4}, \mathrm{Cu}_{2} \mathrm{MgSnS}_{4}, \mathrm{Cu}_{2} \mathrm{FeSnS}_{4}, \mathrm{Cu}_{2} \mathrm{CoSnS}_{4}, \mathrm{Cu}_{2} \mathrm{BaSnS}_{4}$ and $\mathrm{Cu}_{2} \mathrm{NiSnS}_{4}$ [9-14]. These quaternaries can be used in various applications such as: photolysis, sensors, thermoelectricitys, batteries, spintronics and photovoltaics. Copper nickel tin sulfur $\mathrm{Cu}_{2} \mathrm{NiSnS}_{4}$ (CNTS) is presently adaptable compound for photovoltaic solar cells, thanks to its high optical absorption coefficient $\alpha$ (superior to $10^{4} \mathrm{~cm}^{-1}$ ), band gap range of 1.2-1.7 eV and p-type semiconductor material [15-17]. In addition CNTS does not contain scarce and cost chemical elements like indium (In) and gallium (Ga), the elements constituent of CNTS are economical and abundant in earth-crust. The high conversion efficiency of CNTS solar cell absorber layer is $8.2 \%$ achieved by Lu et al. in 2018 [18], this efficiency is near to high efficiency of CZTS absorber material and motive the effort in CCTS compound. Various methods are applied for synthesis CNTS thin films such as: spray pyrolysis [19], electrodeposition [20], solvothermal [21], hydrothermal [22], hot injection [23], spin coating [24], dip-coating [25].

Some groups are studied CNTS thin layers by different preparation methods, Chen et al. elaborate uniform $\mathrm{Cu}_{2} \mathrm{NiSnS}_{4}$ thin layer by electrochemical deposition method and obtain a cubic zinc blend structure, great absorption coefficient and optical energy gap approximated to be $1.2 \mathrm{eV}$ [26]. Yang et al. synthesis CNTS absorber materials using a single step electrodeposition method and found pure stannite structure and optical energy gap around 
$1.61 \mathrm{eV}$ [27]. Ghosh et al. fabricated solar cell based on CNTS absorber layer ITO/ZnO-$\mathrm{NR}$ 'S/ZnS/ $/ \mathrm{Cu}_{2} \mathrm{NiSnS}_{4} / \mathrm{Au}$ under AM1.5 standard light condition and achieved the conversion efficiency of $2.71 \%$ with band gap of $1.74 \mathrm{eV}$, also the solar cell parameters such as: Voc $=0.77$ volts, $\mathrm{FF}=0.537$ and $\mathrm{Jsc}=7.83 \mathrm{~mA} / \mathrm{cm}^{2}$ [28]. Rondiya et al elaborated cubic zinc blend CNTS thin layers the approximated optical band gap energy around $1.57 \mathrm{eV}$ and absorption coefficient over to $10^{5} \mathrm{~cm}^{-1}$. The realized solar cell glass/Mo/CNTS/CdS/Al$\mathrm{ZnO} / \mathrm{Al}$ reported the efficiency $(\eta)$ of $0.09 \%$, Voc equal $423.80 \mathrm{mV}$, Jsc equal $0.52 \mathrm{~mA} / \mathrm{cm}^{2}$ and FF equal 0.43 [29].

In our work we investigate the preparation of CNTS thin films by sol-gel method associated to simple and economical dip-coating on the ordinary glass substrates without sulfurization process. We focused on the effect of dip-coating cycle: 4,5 and 6 using a speed of 50 $\mathrm{mm} / \mathrm{min}$ on the some physical properties such as: structural, compositional, morphological, optical and electrical. We also, calculated some optical parameters including refractive index, extinction coefficient, imaginary and real dielectric constants and optical conductivity to improve the optical devisees.

\section{Experimental detail}

CNTS thin layers were synthesis by sol gel approach, in which the initial solution is elaborated from copper chloride $\mathrm{CuCl}_{2}$ (II), nickl chloride $\mathrm{NiCl}_{2}$ (II), tin chloride $\mathrm{SnCl}_{4}$ (IV) and thiourea $\mathrm{SC}\left(\mathrm{NH}_{2}\right)_{2}$. These precursors, utilized as bases of diverse chemical elements $(\mathrm{Cu}$,

$\mathrm{Ni}, \mathrm{Sn}$ and $\mathrm{S}$ ) in the ratio of: $\frac{\mathrm{Ni}}{\mathrm{Sn}}=1.1, \frac{\mathrm{Cu}}{\mathrm{Ni}+\mathrm{Sn}}=0.85$ and $\frac{\mathrm{S}}{\mathrm{Cu}+\mathrm{Ni}+\mathrm{Sn}}=1.9$. These salts are dissolved in isopropyl alcohol (30\%) and distilled water (70\%), the solution was agitated magnetically during $30 \mathrm{~min}$ at $50{ }^{\circ} \mathrm{C}$. A clear and homogenous green solution was prepared directly after addition of thiourea. The ordinary glass substrates were cleaned with distilled water, diluted nitric acid and isopropyl alcohol. The sol-gel CNTS solution was dip-coated at a speed of $50 \mathrm{~mm} / \mathrm{min}$ on the ordinary glass substrates at a different dip-coating cycle: 4,5 and 6. The CNTS samples were annealed at $300^{\circ} \mathrm{C}$ for $5 \mathrm{~min}$ in air. The thicknesses of CCTS thin films are estimated in the range of 1.60-1.71 $\mu \mathrm{m}$. The dip-coated CNTS samples were characterized using X-ray diffractometer (XRD) with $\mathrm{CuK} \alpha$ radiation $(\lambda=1.54056 \AA)$ in angle 2 theta range of 20-65 degrees (D2 Phaser-Bruker) and Raman spectroscopy using a laser excitation wavelength $\lambda=532 \mathrm{~nm}$ in the Raman shift from 100 to $1000 \mathrm{~cm}^{-1}$ to study structural properties. The compositional and morphological properties were controlled using a energy dispersion X-ray spectroscopy (EDS) and scanning electron microscopy (SEM) (Jeol scanning microscopy IT 100 (JSM-IT 100)). The optical characteristics were studied by using UV-Visible spectrophotometer in the wavelength range of 475-850 nm (Spectrovio junior kit- 
SV2100). The electrical properties were measured using the four point probe method for calculated the resistivity conductivity of CNTS thin films.

\section{Results and discussion}

\section{Structural properties}

Figure 1 presented the X-ray diffraction patterns of CNTS thin films elaborated at different dip-coating cycles. Broad peaks are located at $2 \boldsymbol{\theta}$ around $28.45^{\circ}, 32.56^{\circ}$ and $47.48^{\circ}$ matching respectively to (111), (200) and (220) planes, the high intensity of peak located at $28.45^{\circ}$ of showed privileged direction along (111) plane, the preferentially direction of (111) plane and peaks corresponding proved the formation of cubic CNTS phase corresponding to (JCPDS card No.00-026-0552). These results are similar to the reported using different research groups [14]. No other additional phases are presented in the films deposited at 4 cycles and 5 cycles, we have shown the formation of NiS secondary phase in the film deposited at 6 cycles, the formation of this phases is probably due to high quantity of nickel (Ni) in sample dip-coated at 6 cycles, the high adhesion of Ni compared to Sn for this film lead the Ni allied with sulphur (S) due to high electronegativity of this chemical element. The strong peak at (111) plane show adequate crystalinity of CNTS films, the intensity of (111) plane increased with dip-coating cycle increased, this probably due increasing of grain size of films with increasing of dip-coating cycle.

Crystallite size (D) of CCTS thin layers was approximated from Debye Scherrer's relation (1):

$$
D=\frac{0.94 \lambda}{\beta \cos (\theta)}
$$

where $\lambda$ is the wavelength of the X-ray diffract- meter $(\lambda=1.54056 \AA), \beta$ is the full-width at half maximum (FWHM), $\boldsymbol{\theta}$ is an angle of the Bragg diffraction. The estimated crystallites size of deposited CNTS thin films with different dip-coating cycle is summarized in Table 1. The crystallites size is increased from 6.30 to $9.52 \mathrm{~nm}$ demonstrated the enhancement of thin films quality with dip-coating cycle increased.

Dislocation density $(\rho)$ shows the defect quantity of dip-coater CNTS thin layer structure. " $\rho$ " is distinct as the dislocation length lines per unit volume of the elaborated CNTS semiconductor compound material [30]. In general, great crystallite size of compound thin layers indicates smaller dislocation density [30]. The micro-strain $(\varepsilon)$ is linked to some annealing and deposition conditions, the approximated number of crystallite is calculated using film tackiness (e) and crystallite size (D) of CNTS thin films. To investigate certain structural parameters along (111) plane of CNTS films, dislocation density, micro-strain and crystallite number were approximated following the equations: 


$$
\begin{gathered}
\varepsilon=\frac{\beta \cos (\theta)}{4} \\
\rho=\frac{1}{D^{2}} \\
N=\frac{e}{D^{3}}
\end{gathered}
$$

To control the vibrations modes and to confirm the phase identification of cubic $\mathrm{Cu}_{2} \mathrm{NiSnS}_{4}$ Raman measurements was used for the analyse various samples, we have seen from Figure 2 one Raman peak at $332 \mathrm{~cm}^{-1}$ showed for the samples dip-coated at 4 and 6 cycles is identified for cubic CNTS structure agreeing to results reported in the literatures [31]. No other ternary and binary secondary phases such as: $\mathrm{SnS}_{2}$ (Raman peaks at: 205 and $312 \mathrm{~cm}^{-1}$ ) [32], $\mathrm{SnS}$ (Raman peaks at: 94, 160, 185 and $214 \mathrm{~cm}^{-1}$ ) [33], $\mathrm{Cu}_{2} \mathrm{~S}$ (Raman peaks at: 410, 267 and $475 \mathrm{~cm}^{-1}$ ) [34] and NiS (Raman peaks: 143, 240, 299, 345 and $371 \mathrm{~cm}^{-1}$ [35] exist with CNTS phase. The NiS secondary phase in XRD patterns is not obtained in Raman spectrum of the sample dip-coated at 6 cycles indicated lower quantity of this phase compared to CNTS phase.

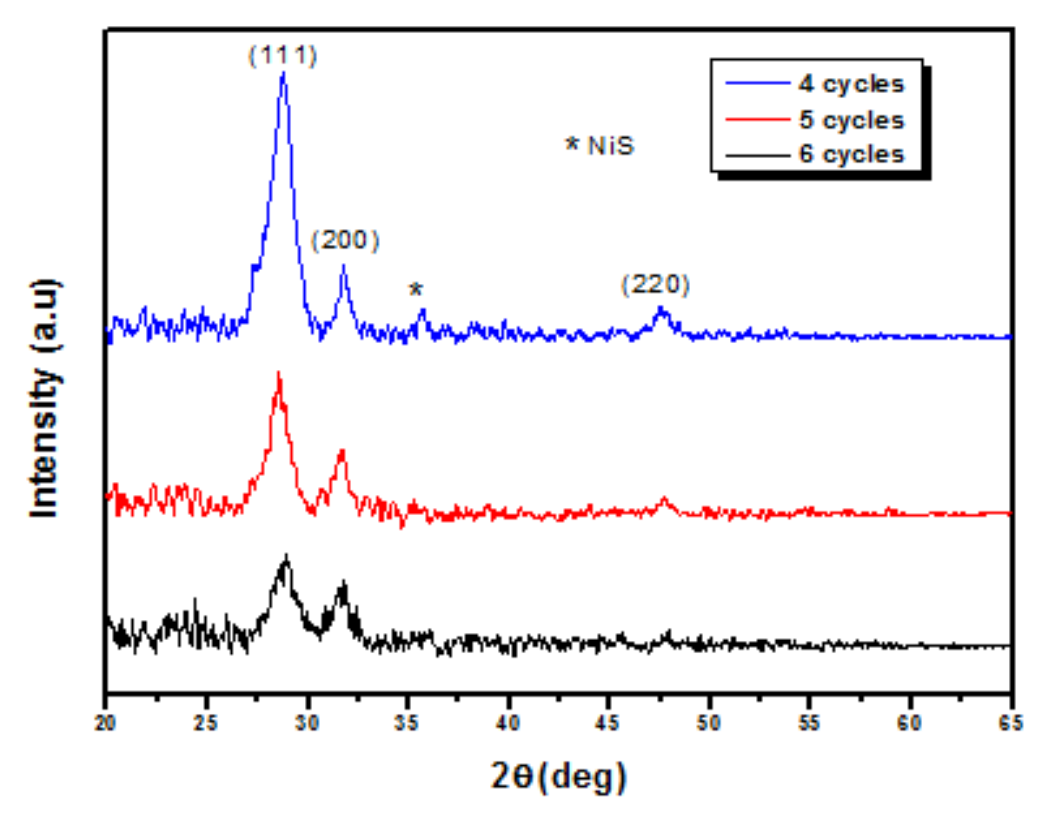

Figure 1: X-ray diffraction peaks of CNTS thin films dip-coated at various cycles 
Table 1: Structural information of $\mathrm{Cu}_{2} \mathrm{NiSnS}_{4}$ thin films at (111) plane

\begin{tabular}{|c|c|c|c|c|}
\hline $\begin{array}{c}\text { Dip-coating } \\
\text { cycle }\end{array}$ & $\begin{array}{c}\text { Crystallite } \\
\text { size D }(\mathrm{nm})\end{array}$ & $\begin{array}{c}\text { Dislocation } \\
\text { density }(\rho) \mathrm{x} \\
10^{16}\left(\text { Lines } / \mathrm{m}^{2}\right)\end{array}$ & $\begin{array}{c}\text { micro-strain } \\
(\varepsilon) \times 10^{-2}\end{array}$ & $\begin{array}{c}\text { crystallite } \\
\text { number }(\mathrm{N}) \\
\times 10^{18}\left(\mathrm{~m}^{-2}\right)\end{array}$ \\
\hline 4 & 6.30 & 2.51 & 2.34 & 6.39 \\
\hline 5 & 8.40 & 1.41 & 1.76 & 2.80 \\
\hline 6 & 9.52 & 1.10 & 1.55 & 1.98 \\
\hline
\end{tabular}

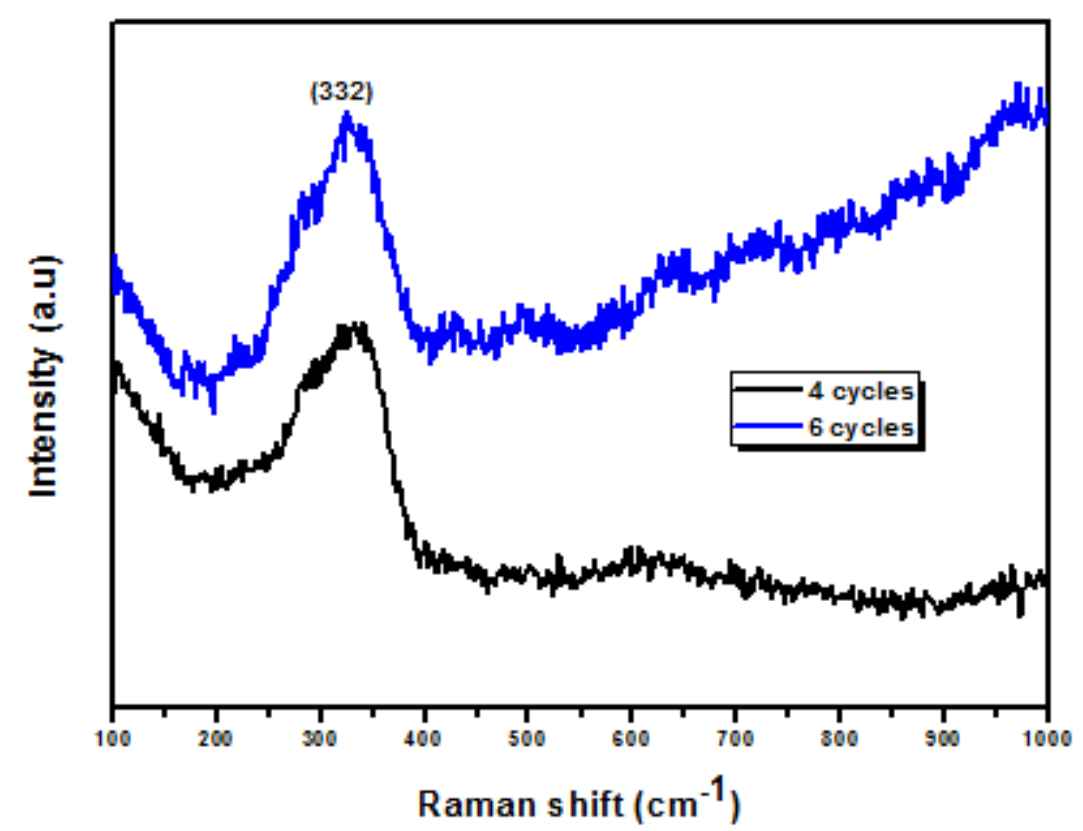

Figure 2: Raman scattering measurements of CNTS deposited at 4 and 6 cycles

\section{Compositional and morphological properties}

Energy dispersion X-ray spectroscopy (EDS) was utilized to control the atomic percentages of four constitutions elements $(\mathrm{Cu}, \mathrm{Ni}, \mathrm{Sn}$ and $\mathrm{S})$ in CNTS layers with various dip-coating cycles. We have indicated from Table 2 the presence of different chemical composition elements of CNTS thin films. The percentage of $\mathrm{Cu}$ is obtained in the range of 17.27-21.15\%, the percentage of $\mathrm{Ni}$ increased with increasing of dip-coating cycle from 8.79 to $16.25 \%$, we have indicated from this results the nickl is more adhesive with increasing of dip-coater cycle, this behaviour confirm the existence of NiS secondary phase in CNTS thin layer deposited at 5 cycles. Also the percentage of Sn decreased with increasing of dip-coating cycle from 21.64 to $14.13 \%$, this behaviour is due increasing of Ni quantity with dip-coating cycle increased, because the quantity of sulphur almost fixe close to ideal percentage $50 \%$ despite of annealing 
without utilization of sulfurization approach in toxic gases like $\mathrm{H}_{2} \mathrm{~S}$ and argon. From the atomic percentages of four chemical elements and the ratios of $\mathrm{Ni} / \mathrm{Sn}, \mathrm{Cu} /(\mathrm{Ni}+\mathrm{Sn})$ and $\mathrm{S} /(\mathrm{Cu}+\mathrm{Ni}+\mathrm{Sn})$ we have shown that CNTS sample dip-coated at 5 cycles is near to stoichiometry. The obtained results are motived the research about CNTS thin layers for photovoltaic solar cells. The EDS spectra of CNTS thin films are showed in Figure 3.

Figure 4 presents the scanning electronic microscope images of CNTS thin films dip-coated at various cycles, we have seen from Figure 4 the all films indicated high quality SEM images uniform without any crack, this images suitable for photovoltaic applications, the film deposited at 4 cycles presented granular surface morphology, the film deposited at 5 cycle indicate the increasing of grain size and high grain size is observed in the film dip-coated at 6 cycles, also the density of films increased with dip-coating increased, this behaviour is due to more adsorption of CNTS material when a deposition of 6 cycles. The uniformity of films indicates the high distribution of copper-nickl-tin-sulphur on the all surface of films and proved the EDS results.

Table 2: EDS analysis of CNTS thin films

\begin{tabular}{|c|c|c|c|c|c|c|c|}
\hline $\begin{array}{c}\text { Dip-coating } \\
\text { cycle }\end{array}$ & $\mathrm{Cu}$ & $\mathrm{Ni}$ & $\mathrm{Sn}$ & $\mathrm{S}$ & $\mathrm{Ni} / \mathrm{Sn}$ & $\mathrm{Cu} /(\mathrm{Ni}+\mathrm{Sn})$ & $\mathrm{S} /(\mathrm{Cu}+\mathrm{Ni}+\mathrm{Sn})$ \\
\hline 4 & 20.66 & 8.79 & 21.64 & 48.91 & 0.40 & 0.67 & 0.95 \\
\hline 5 & 21.15 & 12.47 & 15.13 & 51.13 & 0.82 & 0.76 & 1.04 \\
\hline 6 & 17.27 & 16.25 & 14.13 & 52.35 & 1.15 & 0.56 & 1.09 \\
\hline
\end{tabular}



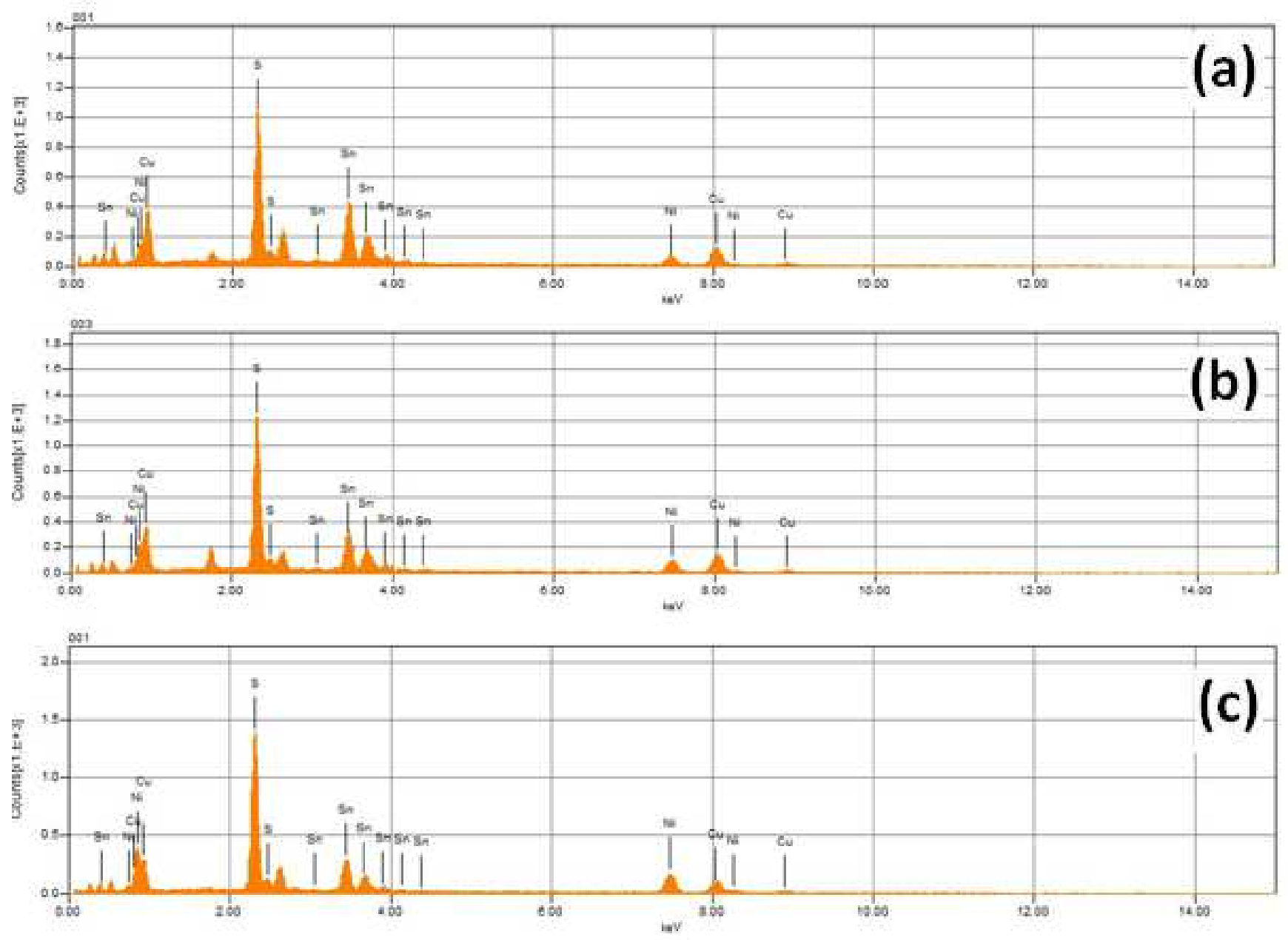

Figure 3: EDS spectra of CNTS thin films deposited at a) 4 cycles, b) 5 cycles and c) 6 cycles 

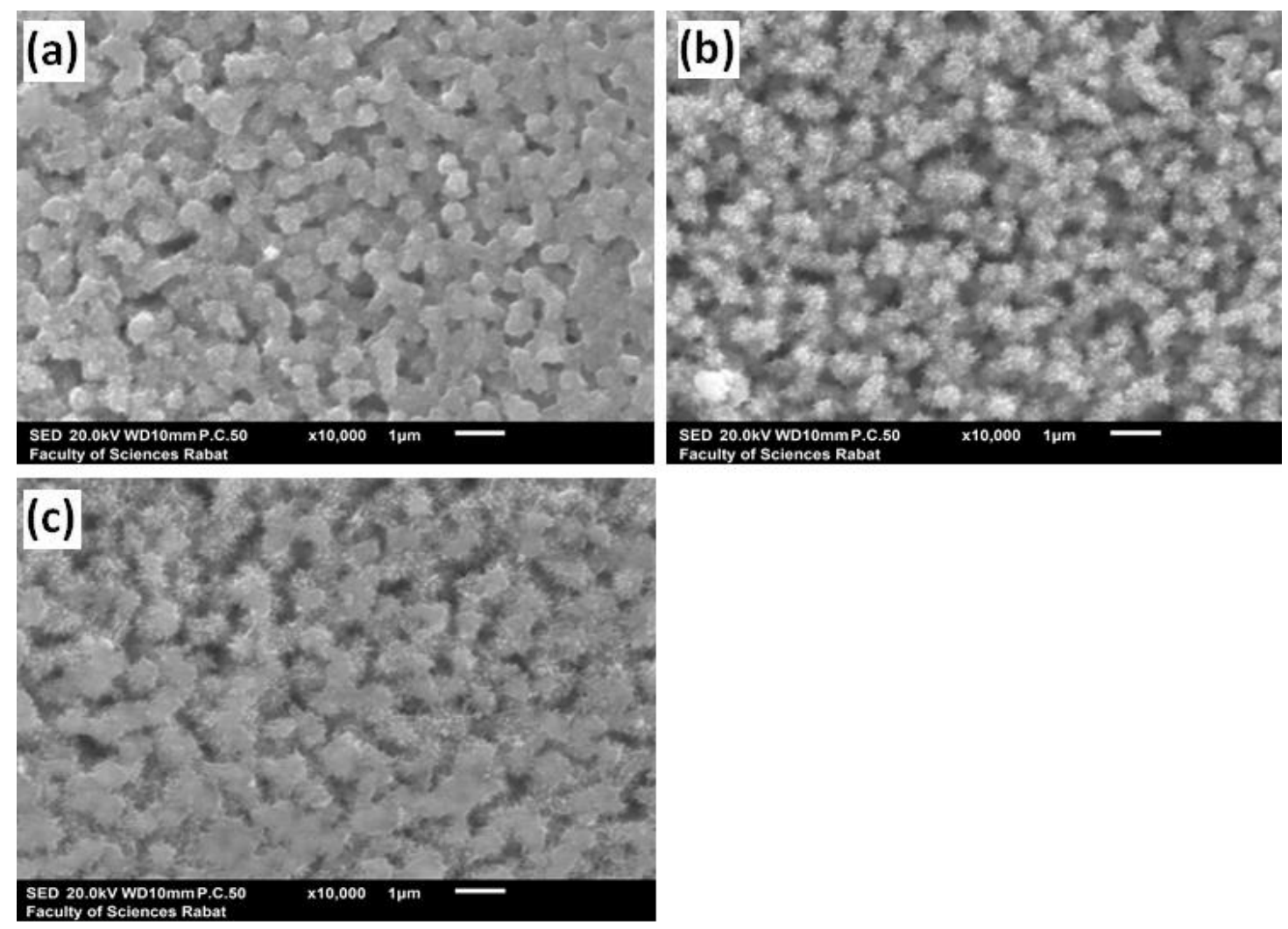

Figure 4: $\mathrm{SEM}$ images of $\mathrm{Cu}_{2} \mathrm{NiSnS}_{4}$ thin films dip-coated at a) 4 cycles, b) 5 cycles and c) 6 cycles

\section{Optical properties}

We can evaluate transmittance $(\mathrm{T})$ and absorbance (Abs) spectra from spectrophotometer UV-vis to investigate the absorbance and transparency of films, Figure 5 shows optical transmittance as function of wavelength $\lambda$ in the range of $475-850 \mathrm{~nm}$, we can show from this figure the transmittance of thin films decrease with dip-coating cycle increased, the maximum transmittances of CNTS thin films deposited at 4, 5 and 6 cycles are $14.14 \%, 10.84 \%$ and $9.83 \%$ respectively, this behaviour is due to the more absorption of incident photon energy from CNTS thin films with dip-coating increased, also due increasing of films thickness with increasing of adsorption layers, in addition the decreasing of transmittance spectra with increasing of annealing temperature confirm the increasing of film densities. The low transmittances demonstrate that CNTS is suitable as absorber material in the solar cell based thin layers. Figure 6 indicates the variation of optical absorbance versus wavelength $\lambda$. The optical absorbance spectra increased with annealing temperature increased, the values of optical absorbance in the wavelength $475 \mathrm{~nm}$ are 1.34, 1.56 and 1.80 for the CNTS films deposited at 4, 5 and 6 cycles respectively, these values motived the future research on CNTS thin films as alternative absorbers materials for solar cells applications. These results are comparable to the reported Ramírez et al. for sprayed $\mathrm{Cu}_{2} \mathrm{ZnSnS}_{4}$ [36], also, Ghediya et al. for 
CCTS absorber materials deposited by dip-coating technique [37] and Elsaeedy for CNTS absorber layers deposited by spray pyrolysis method [14].

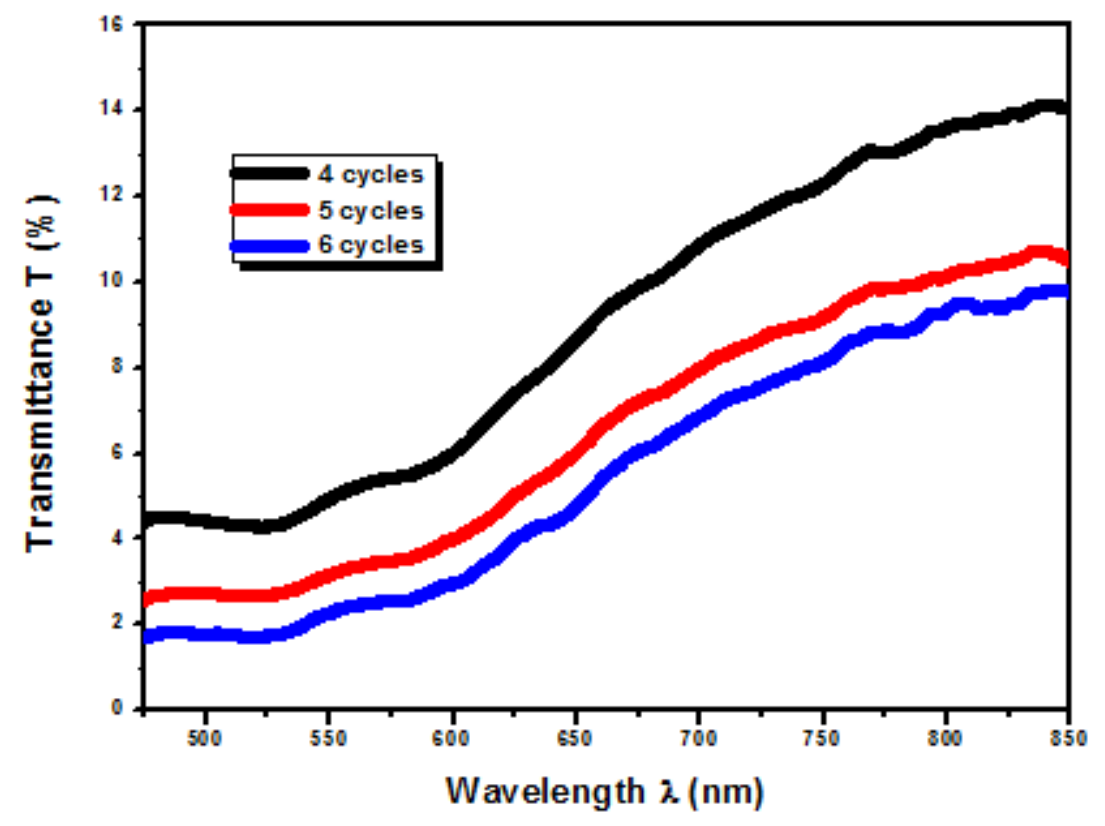

Figure 5: Transmittance data as a function wavelength $\lambda$ of CNTS absorber layers

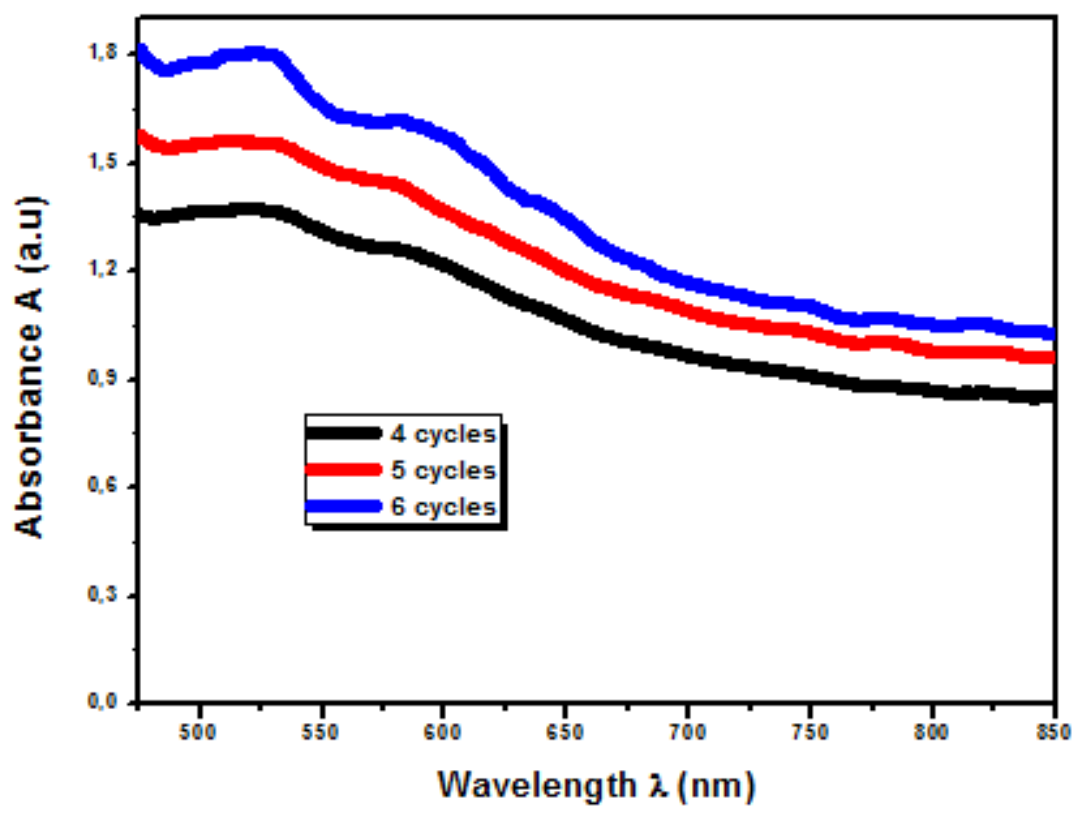

Figure 6: Absorbance spectra as a function of wavelength $\lambda$ of CCNTS absorber layers

Optical absorption coefficient $(\alpha)$ of $\mathrm{Cu}_{2} \mathrm{NiSnS}_{4}$ thin layers is calculated from film thickness and optical absorbance data using relation (5) [38]. Figure 7 presents the variation of absorption coefficient values as a function of wavelength $\lambda$, the absorption coefficient increased with dip-coating cycle and these values are in the range of $1.20-2.38 \times 10^{4} \mathrm{~cm}^{-1}$. The 
values of " $\alpha$ " are comparable to other research works on thin films absorber layers $[19,38$, 39], these values are adaptable to photovoltaic conversion solar energy.

$$
\alpha=\frac{1}{e} \ln \left(\frac{100}{T}\right)
$$

The optical energy gap is an essential in optical devices, the band gap of thin film absorber layer is considered the lower compared to buffer and window thin films in solar cell, the band gap of window layer is considered the higher for maximise the transmittance of photon energy from this layer, the band gap of buffer layer is higher than the band of absorber layer and lower than the band gap of window layer, the role of this layer is to avoid electron hole recombination, so to found adaptable absorber material it is necessary to obtain the band gap range of 1.4-1.7 eV [40, 41$]$. The band gap of CNTS layers is estimated from Tauc's relation (6):

$$
(\alpha h v)=A\left(h v-E_{g}\right)^{m}
$$

where A is proportionality constant; $\mathrm{h}$ is constant of Planck's, $\mathrm{m}$ is signifies the transition nature, $\mathrm{m}$ can take up a $\frac{1}{2}$ for direct allowed change and 2 for an indirect allowed change, 3 for indirect forbidden change, and $\frac{3}{2}$ for direct forbidden change. The CNTS absorber semiconductor has a direct allowed variation. The optimum band gap of quaternary absorber layers is $1.5 \mathrm{eV}$. The optical energy gap was estimated by extrapolating the lined part of $(\alpha h v)^{2}$ v.s h $v$ to $(\alpha h v)=0$ shown in Figure 8. The band gap energies are 1.64, 1.56 and $1.5 \mathrm{eV}$ for CNTS samples dip-coater at 4, 5 and 6 cycles, the band gap decreased with increasing of dip-coating cycle, this behaviour is probably due to increasing of film tackiness, and increase in density of CNTS thin films with dip-coating increased. The NiS secondary phase is not affect negatively the band gap. These results are similar to the archived by Bakr et al. of CZTS thin films synthesis by chemical spray pyrolysis [42], also Maldara et al. for CCTS thin films prepared by spray pyrolysis method [43], and Abed et al. for sprayed CNTS absorber materials [44]. The band gap of $1.5 \mathrm{eV}$ showed of CNTS thin film dip-coated at 6 cycles is the theoretical optimum value of semiconductors absorber thin films of solar cells realization [45]. 


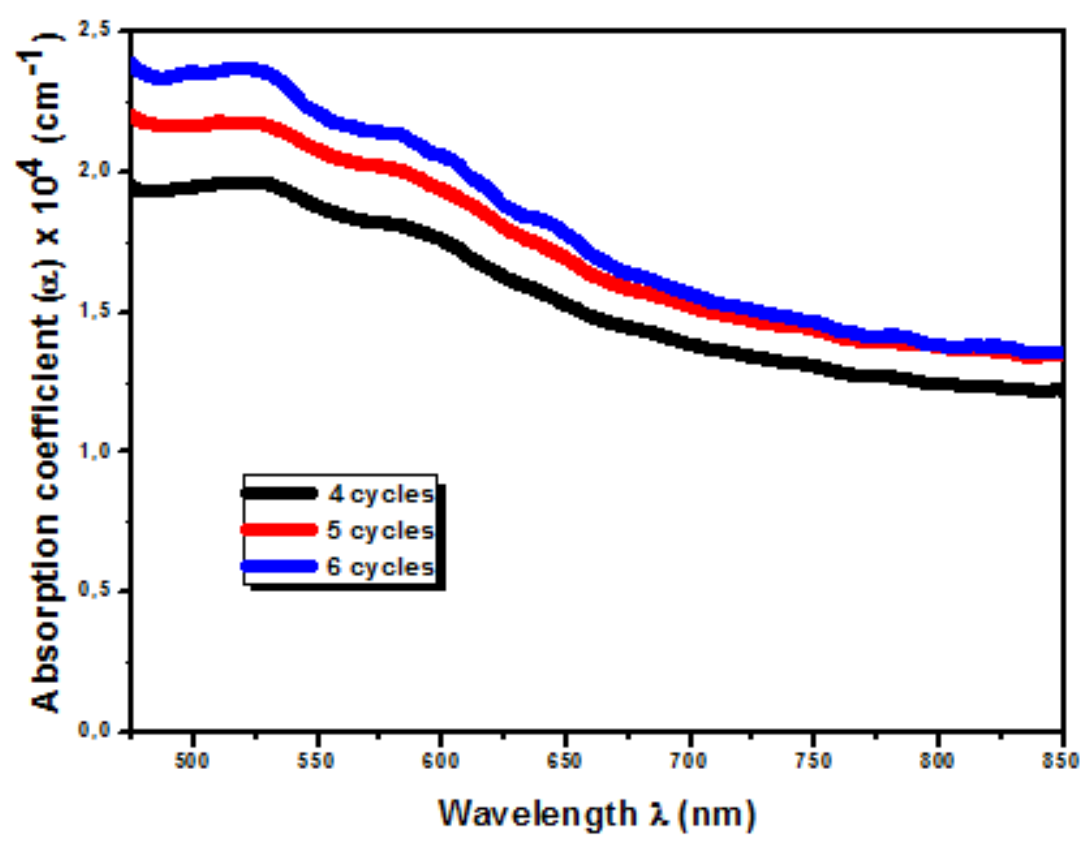

Figure 7: Absorption coefficient of CNTS absorber materials

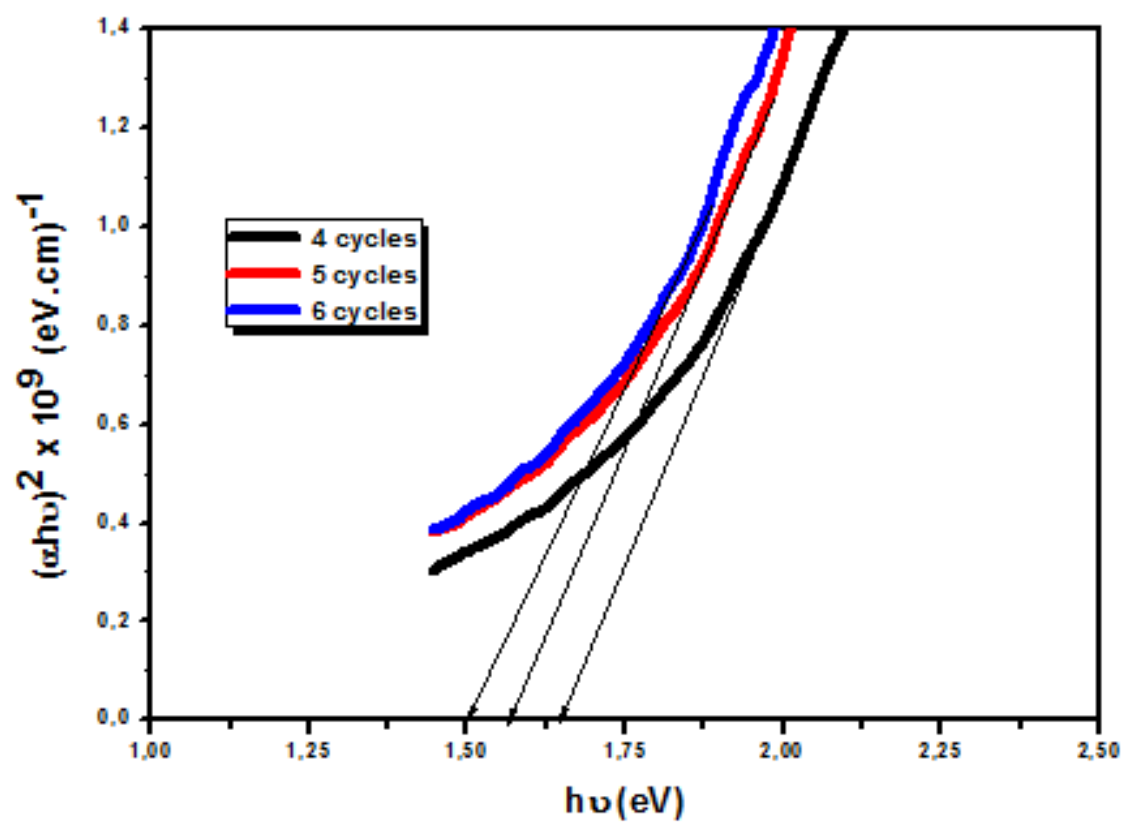

Figure 8: Approximation of band gap by extrapolation method from the variation of $(\alpha h v)^{2}$ as a function of $h v$ for $\mathrm{Cu}_{2} \mathrm{NiSnS}_{4}$ thin films

The investigation of optical parameters such as: refractive index (n), extinction coefficient $(\mathrm{k})$, Real $\left(\varepsilon_{\mathrm{r}}\right)$ and imaginary $\left(\varepsilon_{\mathrm{i}}\right)$ dielectric constants and optical conductivity $\left(\sigma_{\mathrm{opt}}\right)$ is interested for the amelioration and enhancement of solar cells devices. Refractive index is the more critical optical parameter of semiconductor thin films, because of its linked to electronic polarization and local field interior semiconductor material. Figure 9 shows the optical 
refractive index as a function of wavelength $\lambda$, from this figure 9 and Table 3 we have shown that refractive index is increased with annealing approach increased; the greater values of " $n$ " of the dip-coater CNTS thin films with dip-coating cycle increased can be clarified by the densification of our layers. When dip-coating cycle increased, the surface morphology is more and more dense and this reasons a decrease in the light speed through the CNTS absorber layer and this leads to increase the values of " $n$ ". This result is in good agreement with SEM images of CNTS thin films, which present densely packed surface morphology for high dip-coating cycle. It can be, consequently, concluded that a thin layer with a most density present the strong refractive index values giving in figure 4 , the decreasing of refractive index are decreased with rise of wavelength $\lambda$ indicate normal dispersion behaviour. The values of refractive index are in the range of 2.71-5.69 in the wavelength from $475 \mathrm{~nm}$ to $850 \mathrm{~nm}$, these values are appropriate for CNTS compound for solar cells applications. Also are compared to those reported by other research studies for absorber materials [46, 47].

The extinction coefficient $(\mathrm{k})$ shows the total optical waste bring around by scattering and optical transmittance of incident light. Similarly, the parameter "k" signifies the quantity of absorption photon energy in the thin layer semiconductor material, which means the extenuation of an electromagnetic wavelength that is traveling in a thin film material, Figure 10 presents the optical extinction coefficient as a function of wavelength $\lambda$, from figure 10 and Table 3 we have indicate that extinction coefficient increased with dip-coating cycle increased, this behaviour attributed to the increasing of " $\alpha$ " values with increasing of dipcoating cycle, In addition this probably attributed to similar reason specified earlier in the refractive behaviour, the values of extinction coefficient are in the range of $0.033-0.044$, this lesser values are due to strong optical absorbance of all CNTS absorber material, these values are comparable to other groups for absorber layres [48, 49].

$$
\begin{gathered}
n=\frac{1+R}{1-R}+\sqrt{\frac{4 R}{(1-R)^{2}}-k^{2}} \\
k=\frac{\alpha \lambda}{4 \pi}
\end{gathered}
$$

The optical dielectric constant is an intrinsic optical parameter to express the optical behaviour of a thin layer semiconductor material. This parameter can be valued using the values of " $n$ " and the values of " $k$ ". The complex dielectric constant equation is followed using $\varepsilon=\varepsilon_{\mathrm{r}}+\mathrm{i} \varepsilon_{\mathrm{i}}$ where " $\varepsilon_{\mathrm{r}}$ " and " $\varepsilon_{\mathrm{i}}$ " are real and imaginary dielectric constants respectively. " $\varepsilon_{\mathrm{r}}$ " is allied to the deceleration of the light speed and " $\varepsilon_{\mathrm{i}}$ " is related to the interaction of electric fieled with an matter. The values of dielectric constants were calculated using equation and are showed in figures 11 and 12.

$$
\begin{gathered}
\varepsilon_{r}=n^{2}-k^{2} \\
\varepsilon_{i}=2 n k
\end{gathered}
$$


From figure 11 and Table 3 we can show the real dielectric constant is increased with dipcating cycle increased in the wavelength $\lambda$ range of $475-850 \mathrm{~nm}$, this behaviour is attributed to the strong dispersion reason by the increase of dip-coating cycle. The real dielectric constant values are determined from 7.56 to 31.41 in the wavelength range of $475-850 \mathrm{~nm}$. Allowing to relation (9), the values of real dielectric constant are depend usually on the values refractive index $\left(\mathrm{n}^{2}\right)$ due to the values of extinction coefficient $\left(\mathrm{k}^{2}\right)$ are minor compared to $\mathrm{n}^{2}$. Figure 12 shows the imaginary dielectric constant as a function of wavelength $\lambda$, the imaginary dielectric constant increase with dip-coating cycle increased, this behaviour is due to the rise in the extinction coefficient values. The imaginary dielectric values are found ranging from 0.19 to 0.49 . The superior value of "ci" is assigned to the losses made by the optical absorbance. The more optical absorbance can reason major losses inside the thin film material. These found results are good agreement to other research works on absorber materials [39, 47]. The values of optical parameters including: absorption coefficient, refractive index, extinction coefficient, real dielectric constant and imaginary dielectric constant in wavelength $\lambda 800 \mathrm{~nm}$ are tabulated in Table 3 .

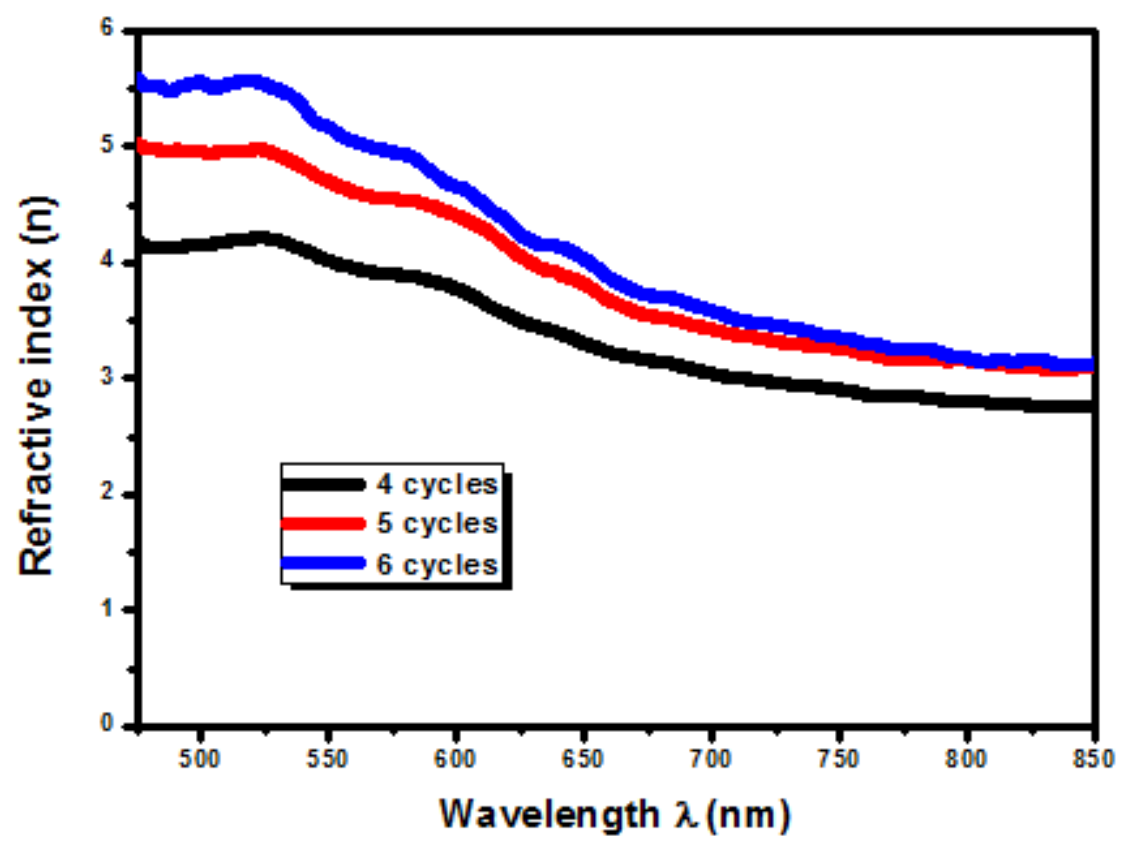

Figure 9: Refractive index versus wavelength $\lambda$ of CNTS thin films 


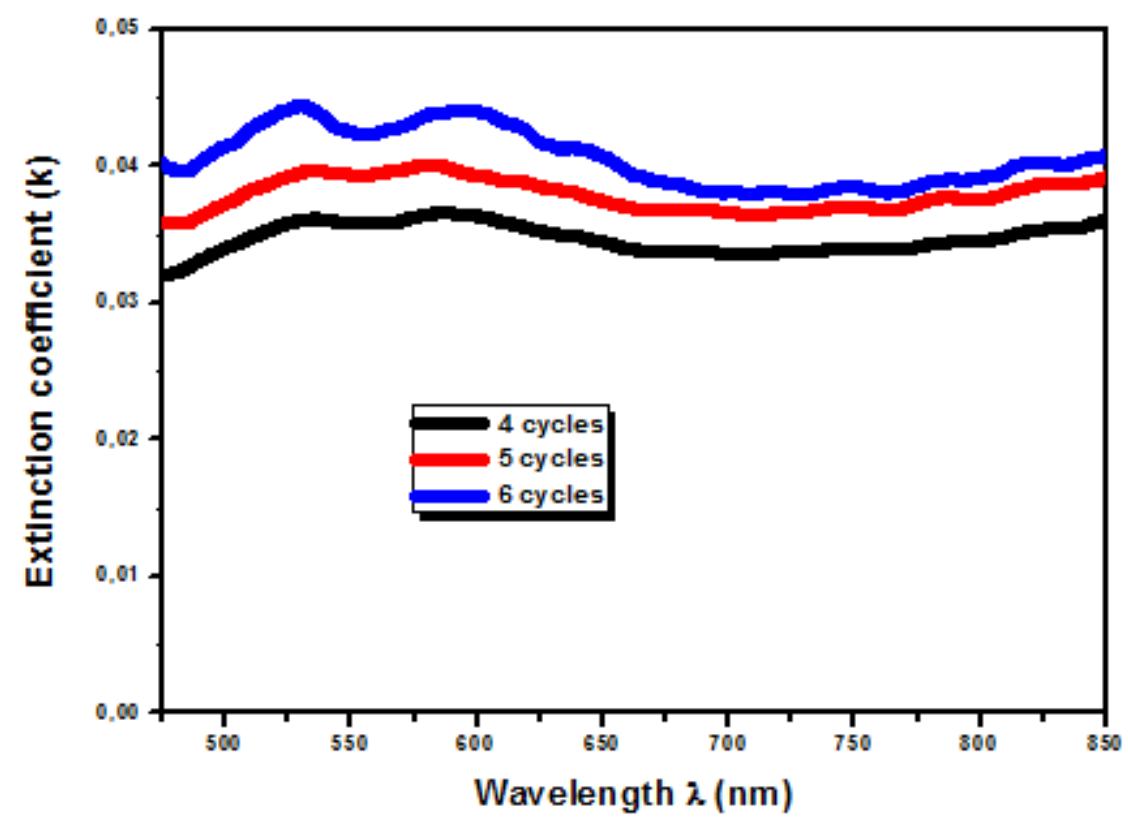

Figure 10: Optical Extinction coefficient versus wavelength $\lambda$ of $\mathrm{Cu}_{2} \mathrm{NiSnS}_{4}$ thin films

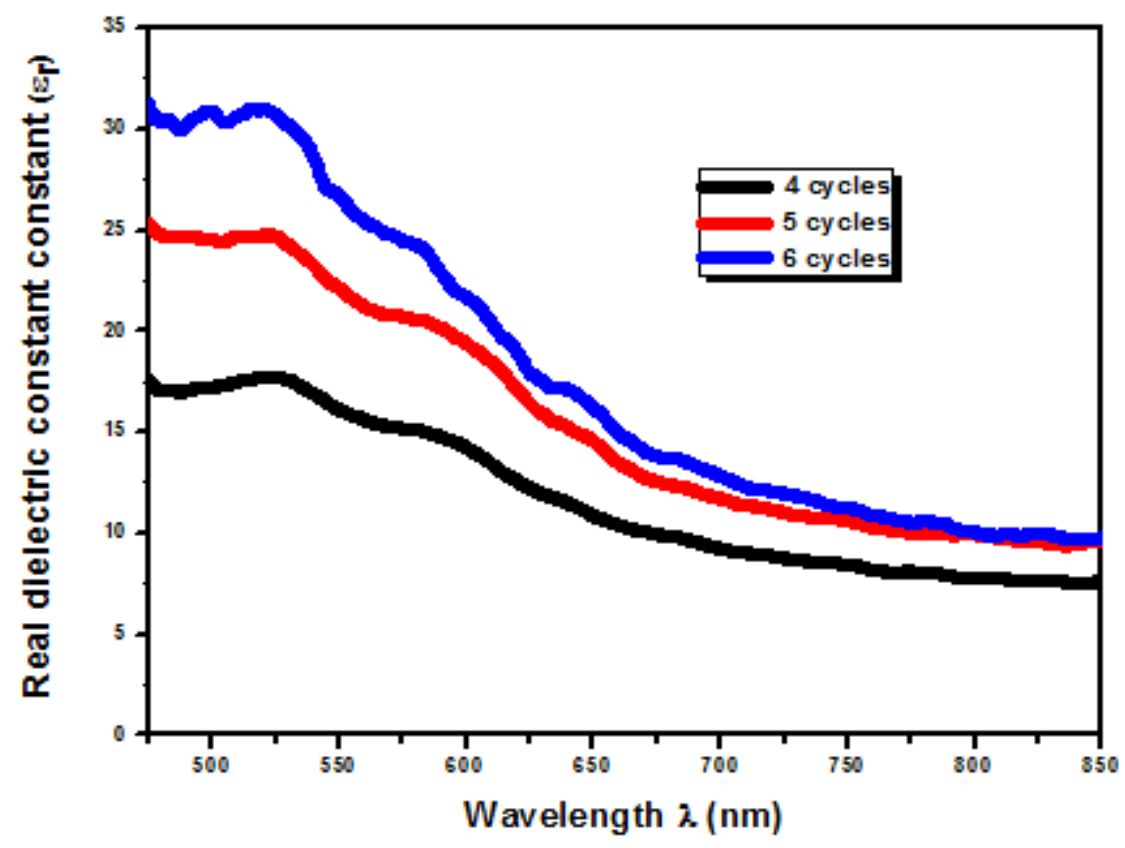

Figure 11: Real dielectric constant of quaternary CNTS thin films 


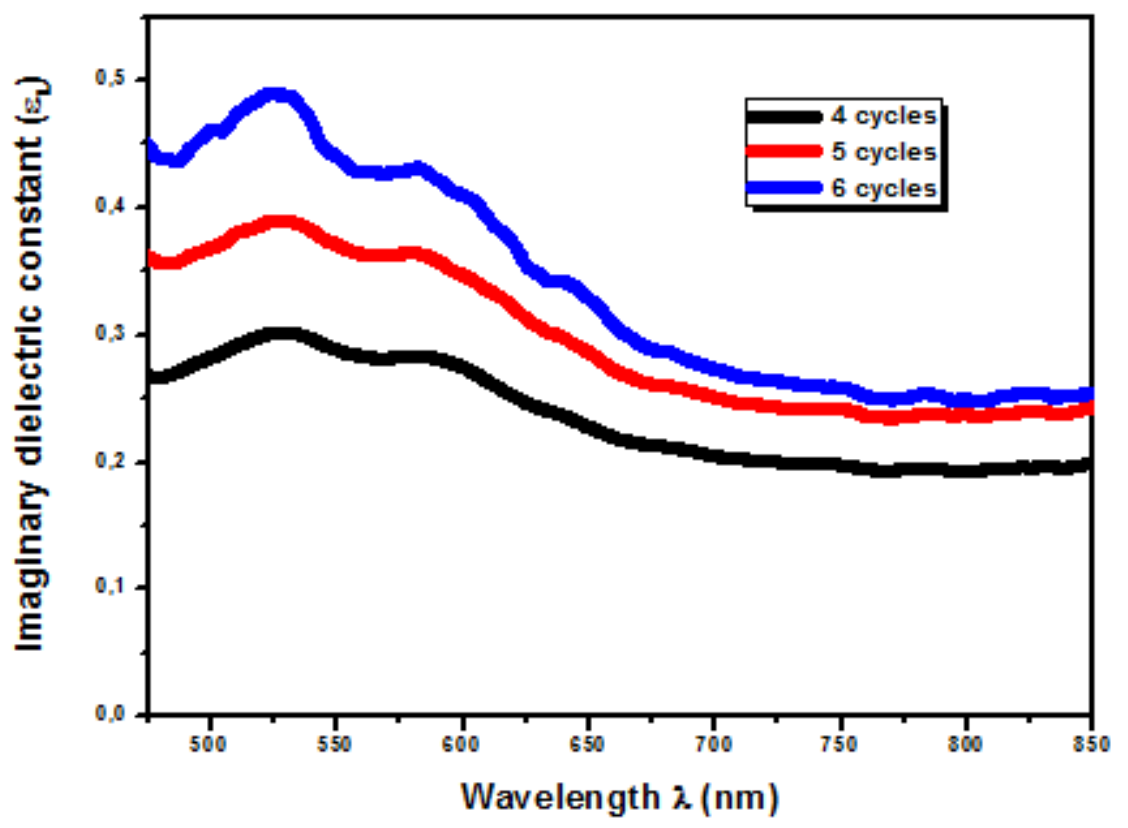

Figure 12: Imaginary dielectric constant of deposited CNTS thin films

Table 4: Values of some optical parametes of $\mathrm{Cu}_{2} \mathrm{NiSnS}_{4}$ absorber materials in the wavelength $\lambda 800 \mathrm{~nm}$

\begin{tabular}{|c|c|c|c|c|c|}
\hline $\begin{array}{c}\text { Dip-coating } \\
\text { cycle }\end{array}$ & $\begin{array}{c}\text { Absorption } \\
\text { coefficient } \\
(\alpha) \times 10^{4} \mathrm{~cm}^{-1}\end{array}$ & $\begin{array}{c}\text { Refractive } \\
\text { index }(\mathrm{n})\end{array}$ & $\begin{array}{c}\text { Extinction } \\
\text { coefficient } \\
(\mathrm{k})\end{array}$ & $\begin{array}{c}\text { Real } \\
\text { dielectric } \\
\text { constant }\left(\varepsilon_{\mathrm{r}}\right)\end{array}$ & $\begin{array}{c}\text { Imaginary } \\
\text { dielectric } \\
\text { constant }\left(\varepsilon_{\mathrm{i}}\right)\end{array}$ \\
\hline 4 & 1.24 & 2.77 & 0.034 & 7.78 & 0.19 \\
\hline 5 & 1.36 & 3.10 & 0.037 & 9.76 & 0.23 \\
\hline 6 & 1.38 & 3.19 & 0.039 & 10.20 & 0.25 \\
\hline
\end{tabular}

The optical conductivity parameter $\left(\sigma_{\mathrm{opt}}\right)$ is a determination of the frequency response of the compound thin layer material when presented to electromagnetic light; " $\sigma_{\mathrm{opt}}$ " is allied to the refractive index (n) and optical absorption coefficient $(\alpha)$ by following equation (11) [50].

$$
\sigma_{o p t}=\frac{c n \alpha}{4 \pi}
$$

Figure 13 indicate the values of optical conductivity versus photon energy hv. We can see from Figure $\mathrm{xx}$ that " $\sigma_{\mathrm{opt}}$ " increase with dip-coating cycle increased in the hv range from 1.5 to $2.6 \mathrm{eV}$, this behaviour is attributed to behaviours of refractive index and extinction coefficient, also " $\sigma_{\mathrm{opt}}$ " increase with photon energy increased, the increase in photon energy advances the number of photo-excited electrons and their movement in thin film. This phenomenon helps the improvement of optical conductivity values. The values of optical 
conductivity are ranging from 0.80 to $3.16 \times 10^{14}\left(\mathrm{~s}^{-1}\right)$, the great values of " $\sigma_{\mathrm{opt}}$ " are due to lesser 1 transmittance and great values of refractive index and absorption coefficient.

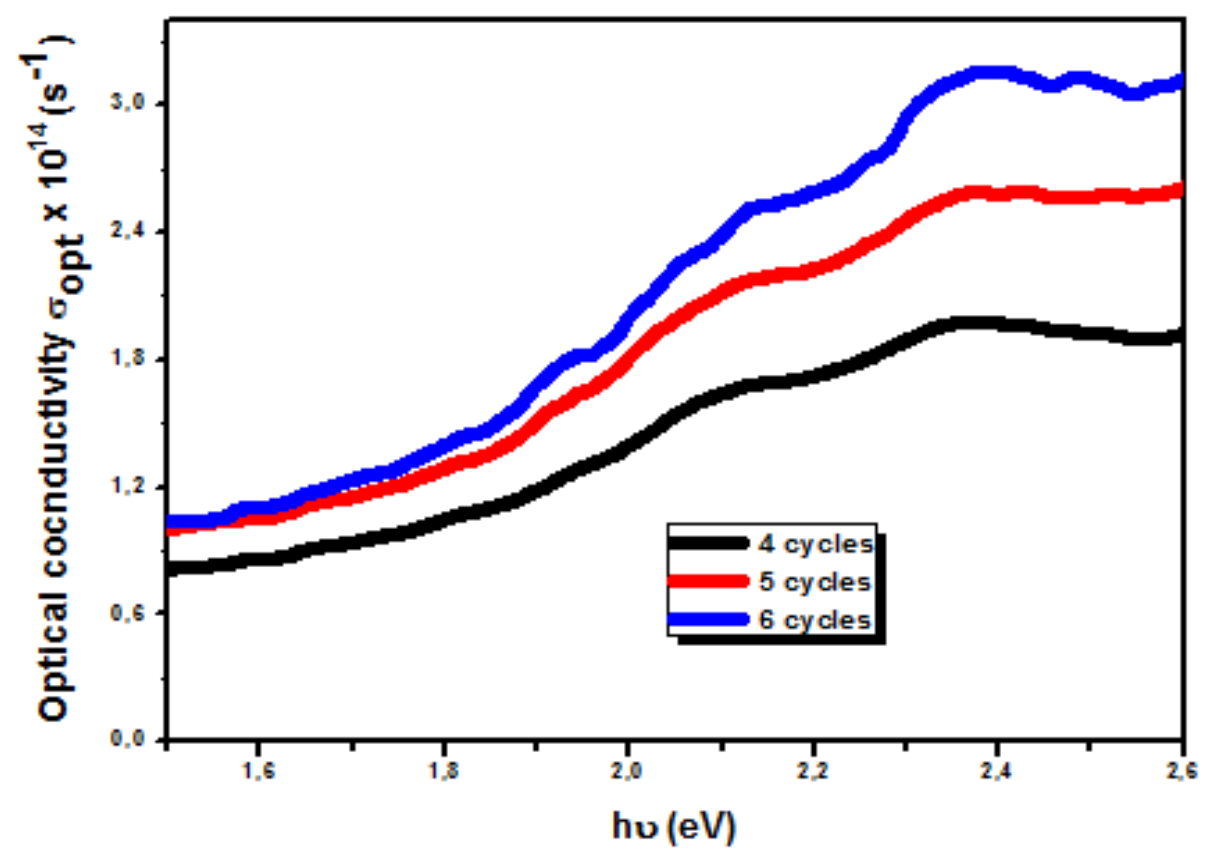

Figure 13: optical conductivity versus photon energy hv of dip-coated CNTS thin films

\section{Electrical properties}

The control of electrical characteristics is significant to investigate the appropriateness of compound semiconductor thin films materials in solar cells applications. Four pointes probe method was employed at room temperature for the study of sheet resistance $\left(\rho_{\text {sheet }}\right)$, resistivity $\left(\rho_{\mathrm{s}}\right)$ and conductivity $\left(\sigma_{\mathrm{s}}\right)$. Generally, the film with great electrical conductivity is more adaptable for photovoltaic energy. The values of " $\rho_{s}$ " were calculated from the determined " $\rho_{\text {sheet }}$ " and film tackiness " $e$ " using equation (11) and " $\sigma_{s}$ " were calculated from the inverse of " $\rho_{\text {sheet" }}$ ".

$$
\rho_{s}=\rho_{\text {sheet }} \times e
$$

We can indicate from Table 4, the sheet resistance values decreased with dip-coating cycle increased, this behaviour is due more density and homogeneity of CNTS sample dip-coater at 6 cycles. The values of resistivity and sheet resistance are comparable to the other research groups [51,52]. The values of electrical conductivity of the films deposited using 4 and 5 cycles are lower, the electrical conductivity of the CNTS thin film deposited at 6 cycles is more adaptable for solar cell applications, probably the existence of secondary phase NiS improve the electrical characteristics of CNTS thin films. 
Table 4: Electrical characteristics of CNTS thin films

\begin{tabular}{|c|c|c|c|}
\hline Dip-coating cycle & $\begin{array}{c}\text { Sheet resistance } \\
\rho_{\text {sheet }}(\mathrm{k} \Omega / \mathrm{sq})\end{array}$ & $\begin{array}{c}\text { Resistivity } \rho_{\mathrm{s}} \\
(\Omega . \mathrm{cm})\end{array}$ & $\begin{array}{c}\text { Conductivity }\left(\sigma_{\mathrm{s}}\right) \\
(\Omega . \mathrm{cm})^{-1}\end{array}$ \\
\hline 4 & 31.84 & 5.09 & 0.0 \\
\hline 5 & 7.86 & 1.30 & 0.76 \\
\hline 6 & 1.44 & 0.24 & 4.16 \\
\hline
\end{tabular}

\section{Conclusion}

In brief, this paper proves the synthesis possibility of $\mathrm{Cu}_{2} \mathrm{NiSnS}_{4}$ thin films using sol-gel dip-coating method on ordinary glass substrates and annealed without sulfurization process. The effect dip-coating cycle and annealing temperature was studied. All CNTS films indicated the formation of cubic structure with a privileged orientation along (111) plane. The crystallite sizes of all CNTS samples are in range between 6.30 and $9.52 \mathrm{~nm}$. Raman experiments were confirmed the existence of cubic CNTS by strong peak at $332 \mathrm{~cm}^{-1}$. The EDS analysis of the sample dip-coated at 5 cycles demonstrated near-stoichiometric CNTS thin film. SEM images present the homogeny films the density of CNTS thin films increased with dip-coating cycle increased, the estimated band gap is in the range of 1.5-1.64 eV, some optical parameters of CNTS thin films such as refractive index, extinction coefficient, real and imaginary dielectric constants and optical conductivity are calculated from transmittance and absorbance spectra to enhance photovoltaic devices. The values of electrical sheet resistance obtained in the range of 1.44-31.84 $(\mathrm{k} \Omega / \mathrm{sq})$ are suitable of CNTS thin films for photovoltaic applications devices.

Acknowledgments- Prof. Bouchaib HARTITI, Senior Associate at ICTP (The Abdus Salam International Centre for Theoretical Physics), is very grateful to ICTP for financial support. Technical support from LMOPS (University of Lorraine, France) is also acknowledged.

\section{Reference}

[1] S. Binetti, A. L. Donne, V. Trifiletti, Front. Chem, 7:297 (2019).

[2] M. A. Green E. D. Dunlop J. Hohl, Ebinger, M. Yoshita; N. Kopidakis, A. W.Y. HoBaillie, Prog Photovolt Res 28:3-15 (2020).

[3] K. Ito and T. Nakazawa, Japanese Journal of Applied Physics, vol. 27, no. Part 1, No. 11, pp. 2094 - 2097, 1988. 
[4] A.V. Moholkar, S.S. Shinde, A.R. Babar, Kyu-Ung Sim, Ye-bin Kwon, K.Y. Rajpure, P.S. Patil , C.H. Bhosale, J.H. Kim, Volume 85, Issue 7, Pages 1354-1363, (2011).

[5] C. Yan, J. Huang, K. Sun, S. Johnston, Y. Zhang, H. Sun, A. Pu, M. He, F. Liu, K. Eder, L. Yang, J. M. Cairney, ,N. J. E-Daukes, Z. Hameiri, J. A. Stride, S. Chen, M. A. Green, and X. Hao, Nature energy, 10, Article number: 2959 (2019).

[6] W. Wang, M.T. Winkler, O. Gunawan, T. Gokmen, T.K. Todorov, Y. Zhu, D.B. Mitzi,. Adv. Energy Mater. 4(7), 6832-6840 (2014).

[7] X. Liu, Y Feng, H. Cui, F. Liu, X. Hao, G. Conibeer, D. B. Mitzi and M. Green, Prog. Photovolt: Res. 24:879-8982016, (2016).

[8] D. Mora-Herrera, R. Silva-González, F.E. Cancino-Gordillo, Mou Pal, Volume 199, PP 246-255, (2020).

[9] L. Chen, H. Deng, J. Tao, H. Cao, L. Huang, L. Sun, P. Yanga and J. Chua, RSC Advances, RSC Adv, 5, 84295-84302, (2015).

[10] G. Yang, X. Zhai, Y. Li, B. Yao, Z. Ding, R. Deng, H. Zhao, L. Zhang, Z. Zhang, Materials Letters 242 pages 58-61, (2019).

[11] A. M. Alanazi, F. Alam, A. Salhi, M. Missous, A. G. Thomas, P. O'Brien and David J. Lewis, RSC Advances, 9, 24146-24153, (2019).

[12] T. Wang, Q. Zhan, W, Cheng, Journal of Materials Science: Materials in Electronics, Vol. 30, N 3, 2285-2291, (2019).

[13] H. Guo, C. Ma, Z. Chen, X. Jia, Q. Cang, N. Yuan, J. Ding, Solar Energy 181, 301-307 (2017).

[14] H. I. Elsaeedy, Journal of Materials Science: Materials in Electronics, 30:12545-12554, (2019).

[15] A. Jariwala, T. K. Chaudhuri, S. Patel, A. Toshniwal, V. Kheraj, A. Ray, Volume 215, , Pages 118-120, (2018).

[16] K. Mokurala, S. Mallick, P. Bhargava, S. Siol, T. R. Klein, M. F.A.M. van Hest, Journal of Alloys and Compounds 725, 510-518 (2017).

[17] L. Shi,Y. Li, and R. Zheng, chem plus chem, 80, 1533 - 1536, (2015).

[18] S. Lu, H. Yang, F. Li, Y. Wang, S. Chen, G. Yang, Y. Liu and X. Zhang, scientific reports pages 1-7 8:8714 (2018).

[19] S. Dridi, N. Bitri, M. Abaab, Mater. Lett. 204, 61-64 (2017).

[20] C.L. Yang, Y.H. Chen,M. Lin, S.L. Wu, L. Li, W.C. Liu, X.S. Wu, F.M. Zhang, Volume 166, Pages 101-104, (2016).

[21] T.-X. Wang, Y.-G. Li, H.-R. Liu, H. Li, S.-X. Chen, Mater. Lett. 124, 148-150 (2014). 
[22] S. Sarkar, B. Das, P.R. Midya, G.C. Das, K.K. Chattopadhyay, Mater. Lett. 152,155-158 (2015).

[23] A. Kamble, K. Mokurala, A. Gupta, S. Mallick, P. Bhargava, Mater. Lett. 137, 440-443 (2014).

[24] D. Ait elhaj, A. El kissani, M. Elyaagoubi, H. Ait dads, F. Welatta, L. Nkhaili, H. Chaib, A. Outzourhit, Volume 107, 104811, (2020).

[25] K. Mokurala, S. Mallick, P. Bhargava, S. Siola, Talysa R.Kleina, M. F.A.M. van Hesta, Journal of Alloys and Compounds, Volume: 725; Journal Issue: C, 25]2525]pages 510-518, (2017).

[26] H-J Chen, S-W-Fu, T-C. Tsai, C-F.Shih, Materials Letters166, 215-218, (2016).

[27] C.L. Yang, Y.H.Chen, M.Lin, S.L.Wu, L.Li, W.C.Liu, X.S.Wu b, F.M.Zhang, Materials Letters166, 101-104 (2016).

[28] A. Ghosh, D. K. Chaudhary, A. Biswas, R. Thangavel, and G. Udayabhanu, RSC Adv. 6, 115204-115212 (2016).

[29] S. Rondiya, N. Wadnerkar, Y. Jadhav, S. Jadkar, S. Haram, and M. Kabir, Chem. Mater., 29, 3133-3142, (2017).

[30] D. Naveena, L. Thirumalaisamy, R. Dhanabal K. Sethuraman, and A. C. Bose, ACS Applied Energy Materials, 3, 11, 10550-10559 (2020).

[31] A. Chihi, M. F. Boujmil, B. Bessais, Journal of Materials Science: Materials in Electronics 30(4), (2019).

[32] Y. Huang, E. Sutter, J. T. Sadowski, M. Cotlet, O. L.A. Monti, D. A. Racke, M. R. Neupane, D. Wickramaratne, R. K. Lake, B. A. Parkinson, and P. Sutter, ACS Nano, 8(10), 10743-10755 (2014).

[33] D. Naveena, L. Thirumalaisamy, R. Dhanabal K. Sethuraman, and A. C. Bose, ACS Applied Energy Materials, 3, 11, 10550-10559 (2020).

[34] T. Chandel, V. Thakur, S. Halaszova, M. Prochazka, D. Hasko, D. Velic, R. Poolla, . J. Electron. Mater. 47(9), 5477-5487 (2018).

[35] M. S-Niasari, F. Davar, H. Emadi, Chalcogenide Letters, Vol. 7, No. 12, p. 647-655 (2010).

[36] E.A. Ramírez , A. Ramírez, G. Gordillo, Materials Science in Semiconductor Processing, Volume 67, Pages 110-117 (2017).

[37] P. R. Ghediya and T. K Chaudhuri, Mater. Res. Express 5, 085509 (2018).

[38] A. Ziti, B. Hartiti, H. Labrim, S. Fadili, A. Ridah, M. Tahri, P. Thevenin, Applied Physics A 125:218 (2019). 
[39] H. I. El Saeedy, H. A. Yakout, M. T. El Sayed, Applied Physics A 126:281 (2020).

[40] P.S. Maldara, M.A. Gaikwada, A.A. Manea, S.S. Nikama, S.P. Desaia, S.D. Girib , A. Sarkarb , A.V. Moholkara, Solar Energy volume 158, Pages 89-99 (2017).

[41] N. Khemiri, S. Chamekha, M. Kanzaria, Volume 207, Pages 496-502 (2020).

[42] N. A. Bakr, S. A. Salman, S. A. Hameed, International Journal of Applied Engineering Research ISSN 0973-4562 Volume 13, pp. 3379-3388, (2018).

[43] P.S. Maldara, M.A. Gaikwada, A.A. Manea, S.S. Nikama, S.P. Desaia, S.D. Girib , A. Sarkarb , A.V. Moholkara, Solar Energy volume 158, Pages 89-99 (2017).

[44] M. A. Abed, N. A. Bakr, J. AL-Zanganawee, Chalcogenide Letters, Vol. 17, No. 4, p. 179 $-186(2020)$.

[45] T. Zdanowicz, T. Rodziewicz, M. Zabkowska-Waclawek, Sol Energy Mater Sol Cells 87:757-769 (2005).

[46] S. Islam, M. A. Hossain, H. Kabir, M. Rahaman, M. S. Bashar, M. A. Gafur, A. Kabir, M. M. R. Bhuiyan, F. Ahmed, N. Khatun, Int. J. Thin. Fil. Sci. Tec. 4, No. 3, 155-161 (2015).

[47] A. Kotbi, B. Hartiti, S. Fadili, A. Ridah, P. Thevenin, Appl. Phys. A 123:379 (2017).

[48] Ahmed Saeed Hassanien, I.M. El Radaf, Physica B. Condensed Matter Volume 585, 15, 412110, (2020).

[49] A. Ziti, B. Hartiti, H. Labrim, S. Fadili, A. Batan, M. Tahri, A. Ridah, O. Mounkachi A. Benyoussef and P. Thevenin, Journal of Materials Science: Materials in Electronics 30:13134-13143 (2019).

[50] K. Sharma, A.S. Al-Kabbi, G.S.S. Saini, S.K. Tripathi, Mater. Res. Bull. 47, 1400-1406 (2012).

[51] S. Dridi, E. Aubry, N. Bitri, F. Chaabouni and P. Briois, Coatings 10, 963, (2020).

[52] X. Yu, A. Ren, F. Wang, C. Wang, J. Zhang, W. Wang, L. Wu, W. Li, G. Zeng, and L. Feng, International Journal of Photoenergy Volume 2014, Article ID 861249, 6 pages (1-6) (2014). 
Figures

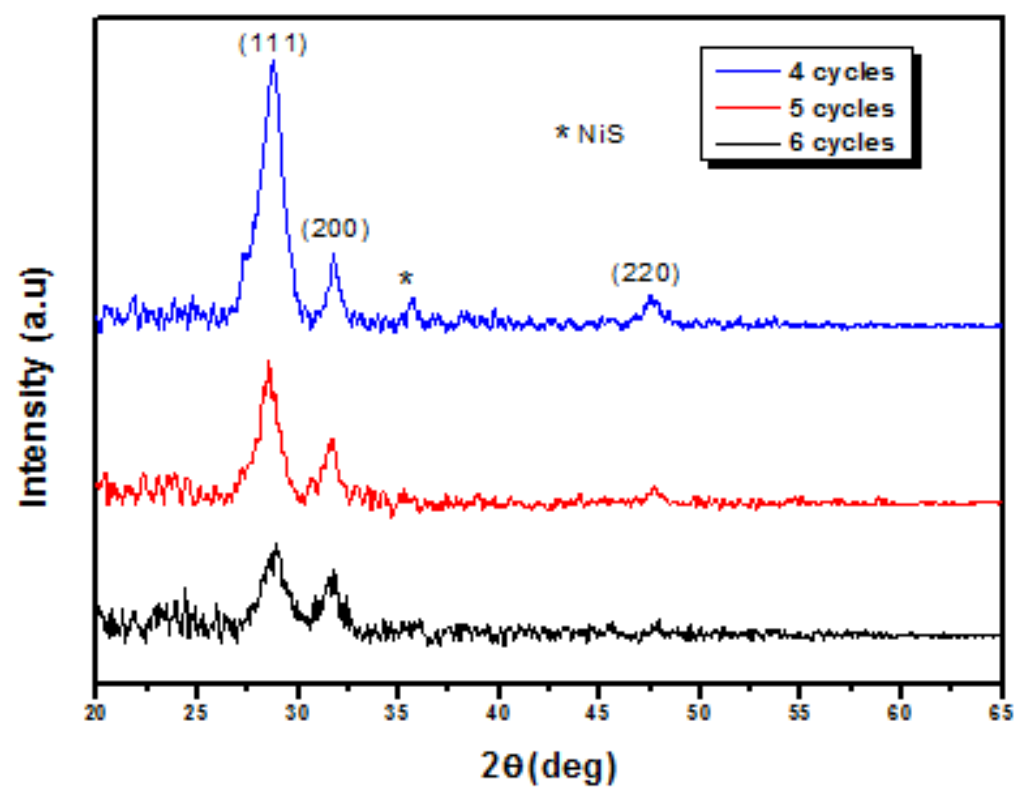

Figure 1

X-ray diffraction peaks of CNTS thin films dip-coated at various cycles

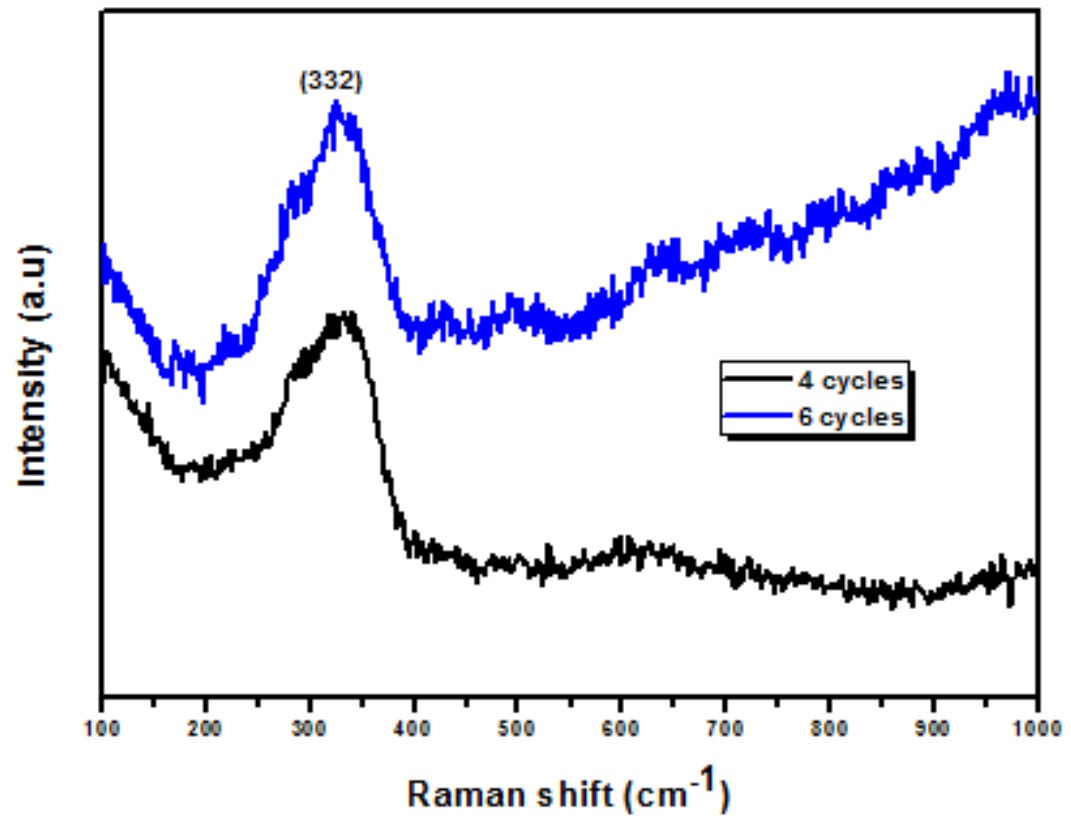

Figure 2

Raman scattering measurements of CNTS deposited at 4 and 6 cycles 

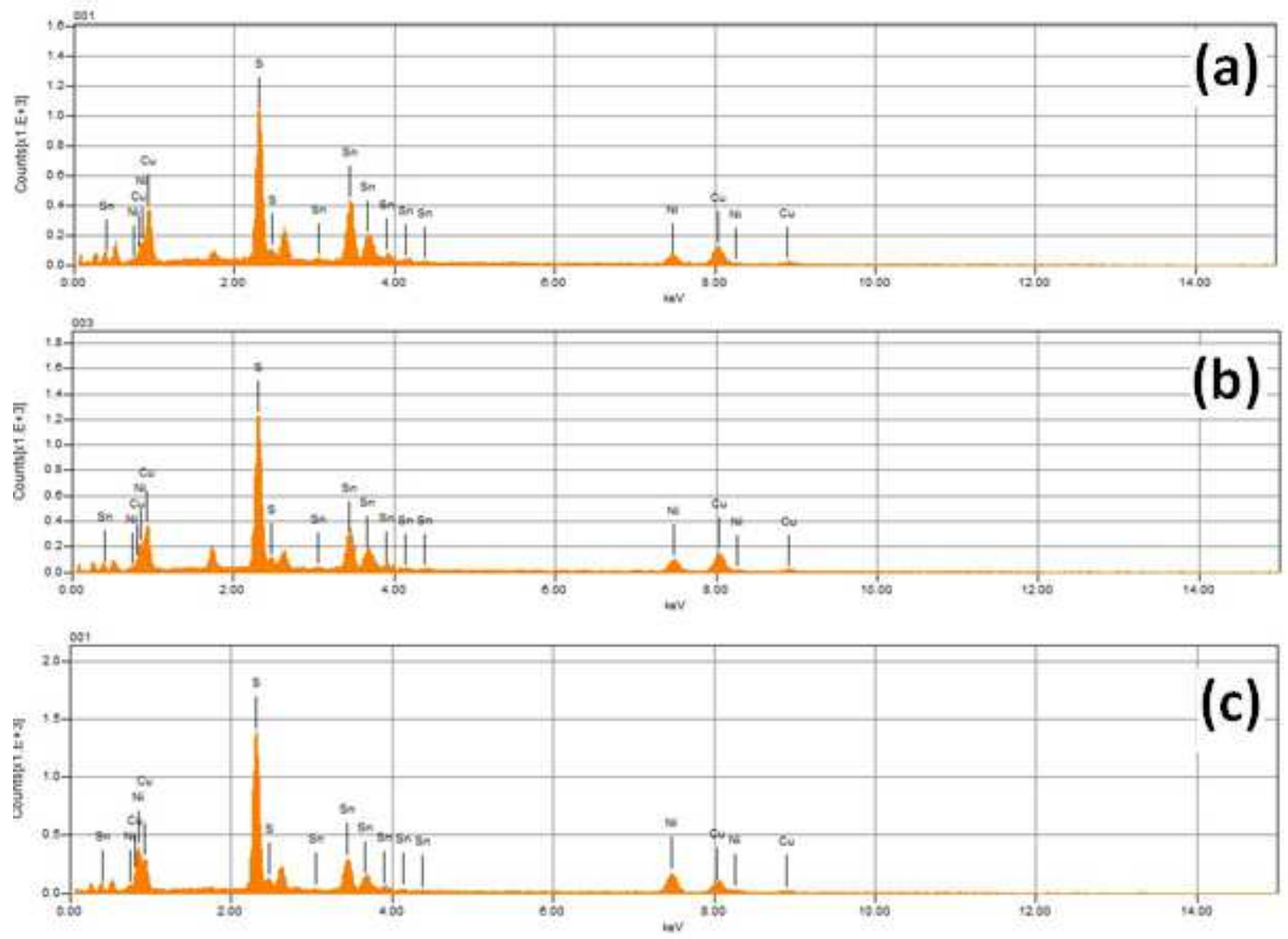

Figure 3

EDS spectra of CNTS thin films deposited at a) 4 cycles, b) 5 cycles and c) 6 cycles 

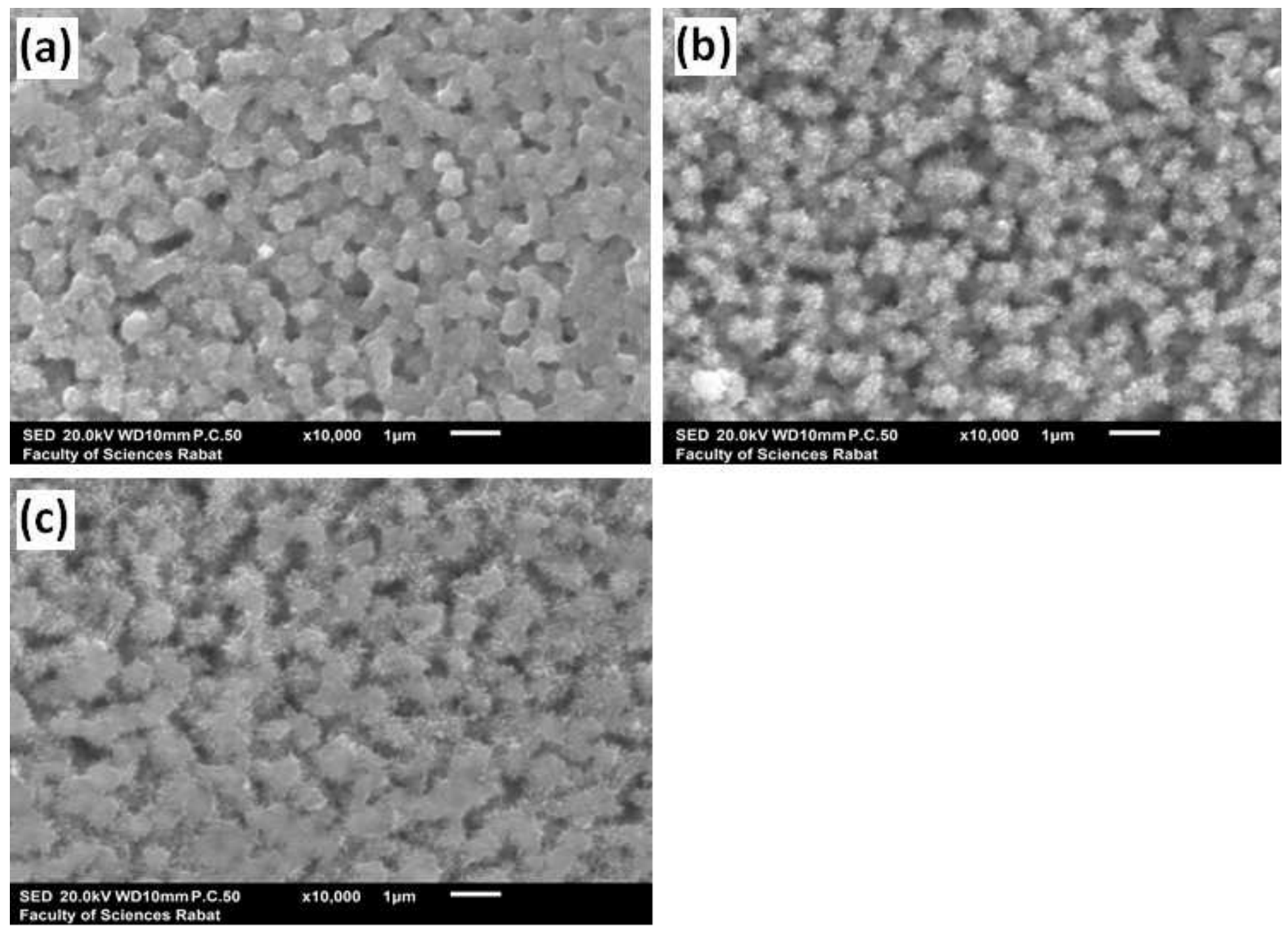

Figure 4

SEM images of Cu2NiSnS4 thin films dip-coated at a) 4 cycles, b) 5 cycles and c) 6 cycles

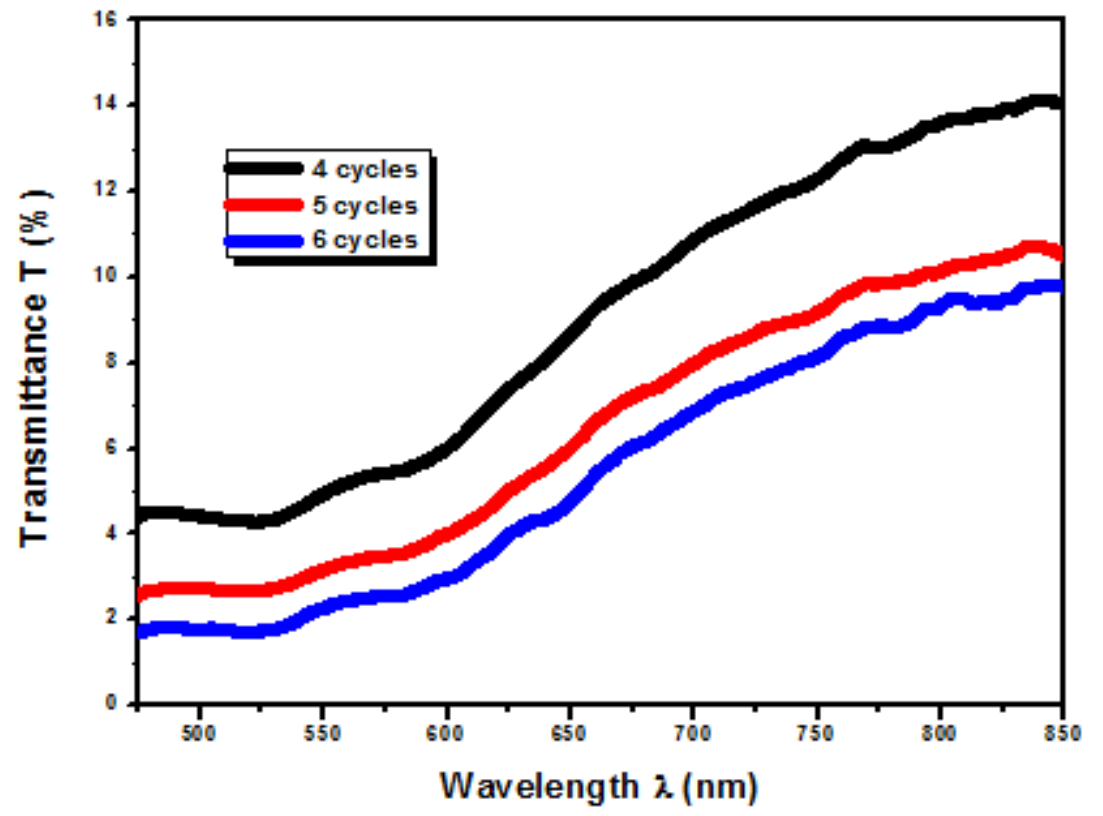


Figure 5

Transmittance data as a function wavelength $\lambda$ of CNTS absorber layers

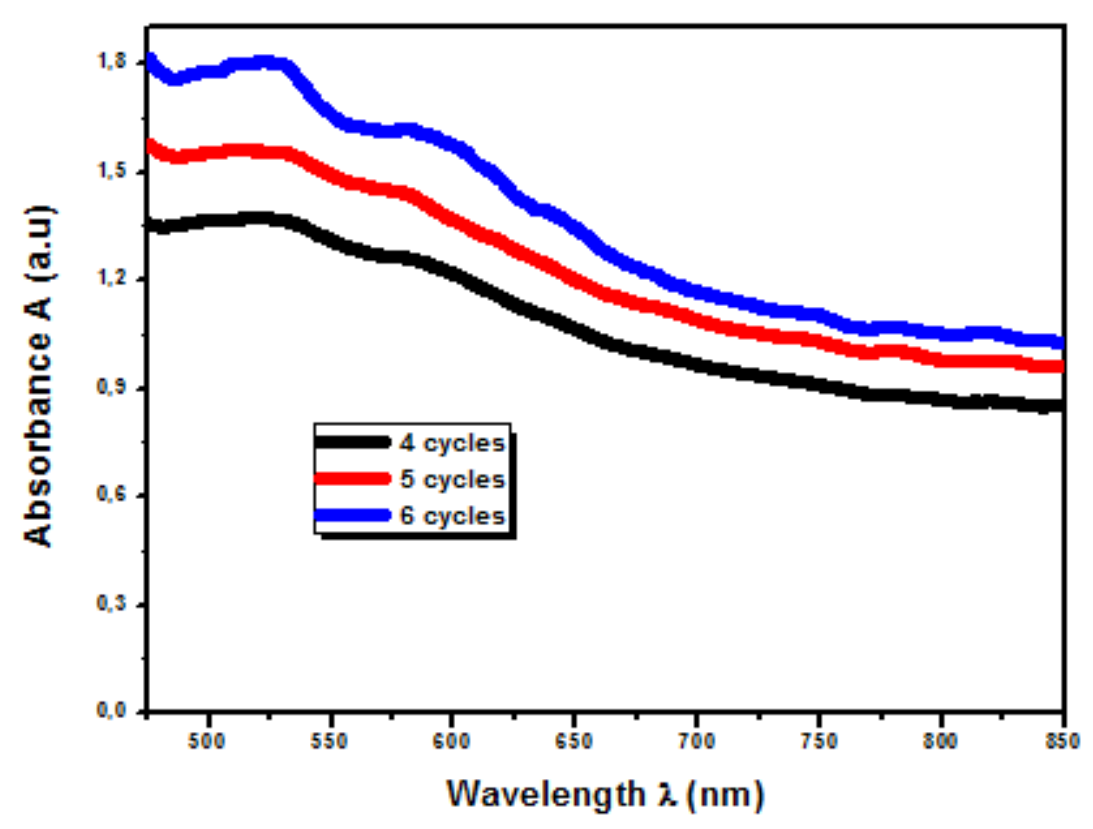

Figure 6

Absorbance spectra as a function of wavelength $\lambda$ of CCNTS absorber layers

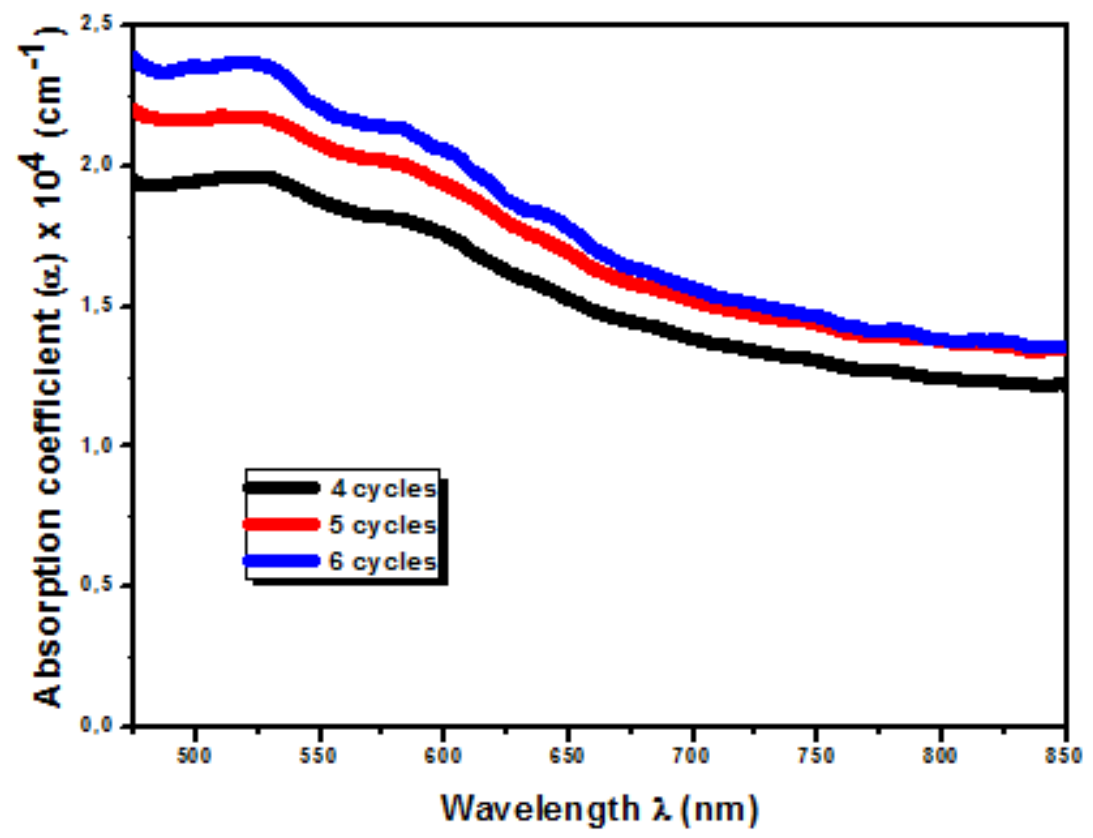

Figure 7

Absorption coefficient of CNTS absorber materials 


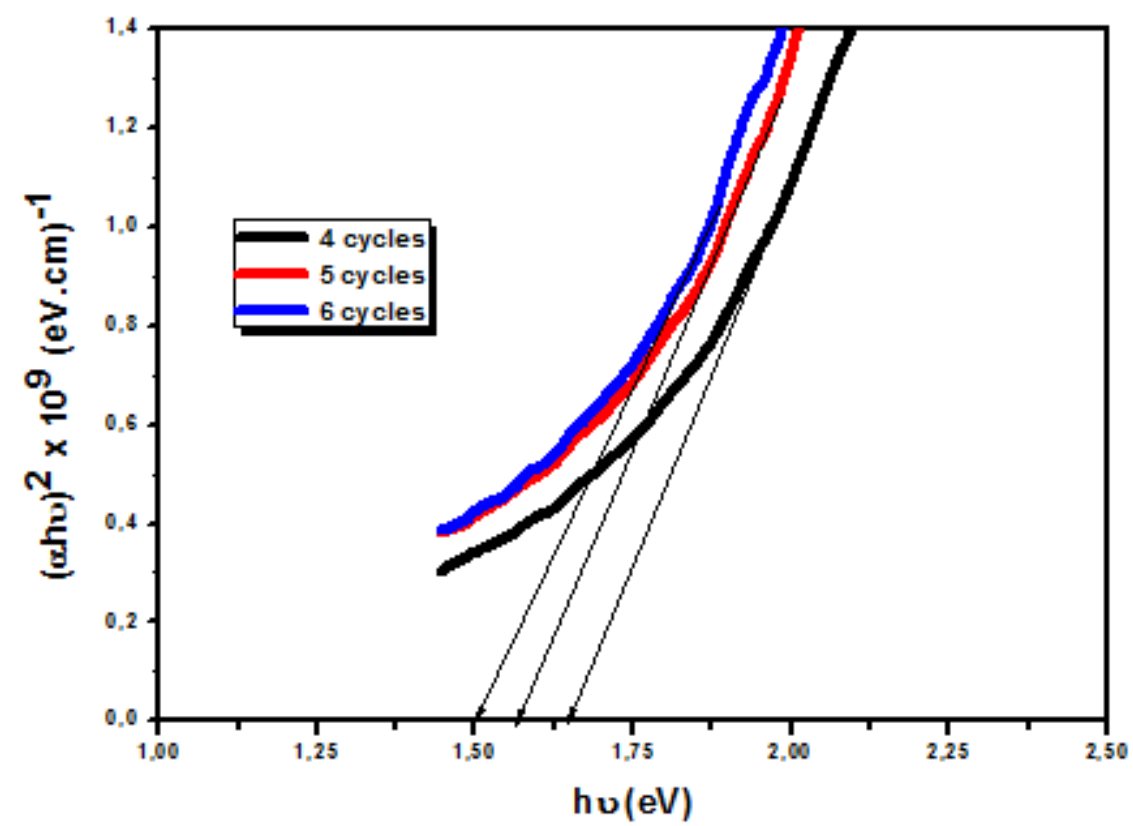

Figure 8

Approximation of band gap by extrapolation method from the variation of (ahv)2 as a function of hv for Cu2NiSnS4 thin films

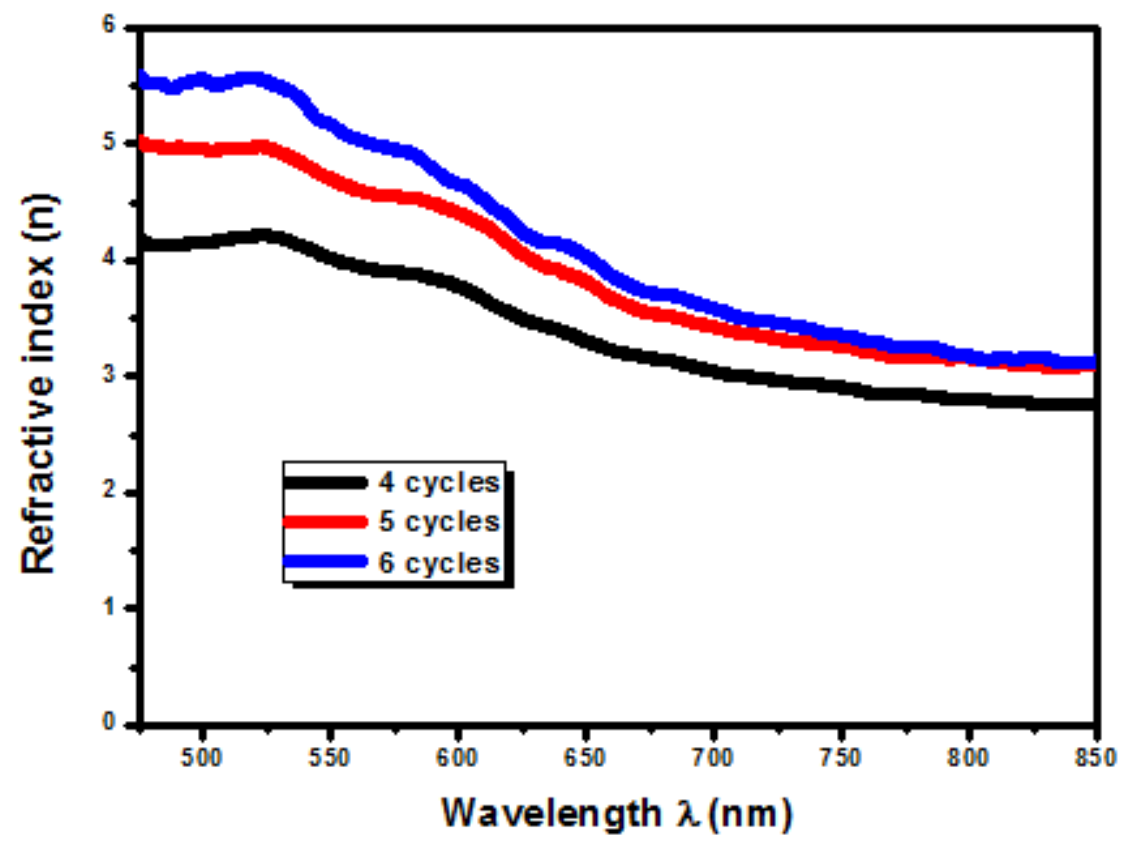

Figure 9

Refractive index versus wavelength $\lambda$ of CNTS thin films 


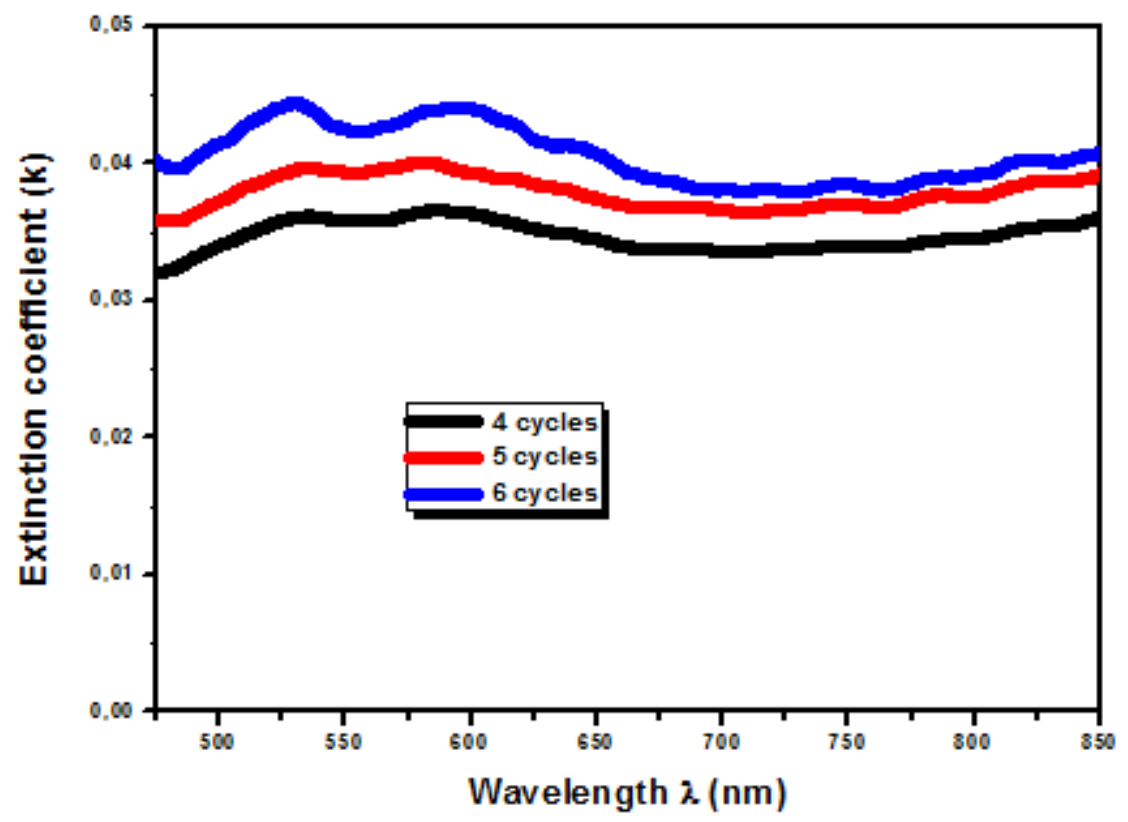

Figure 10

Optical Extinction coefficient versus wavelength $\lambda$ of Cu2NiSnS4 thin films

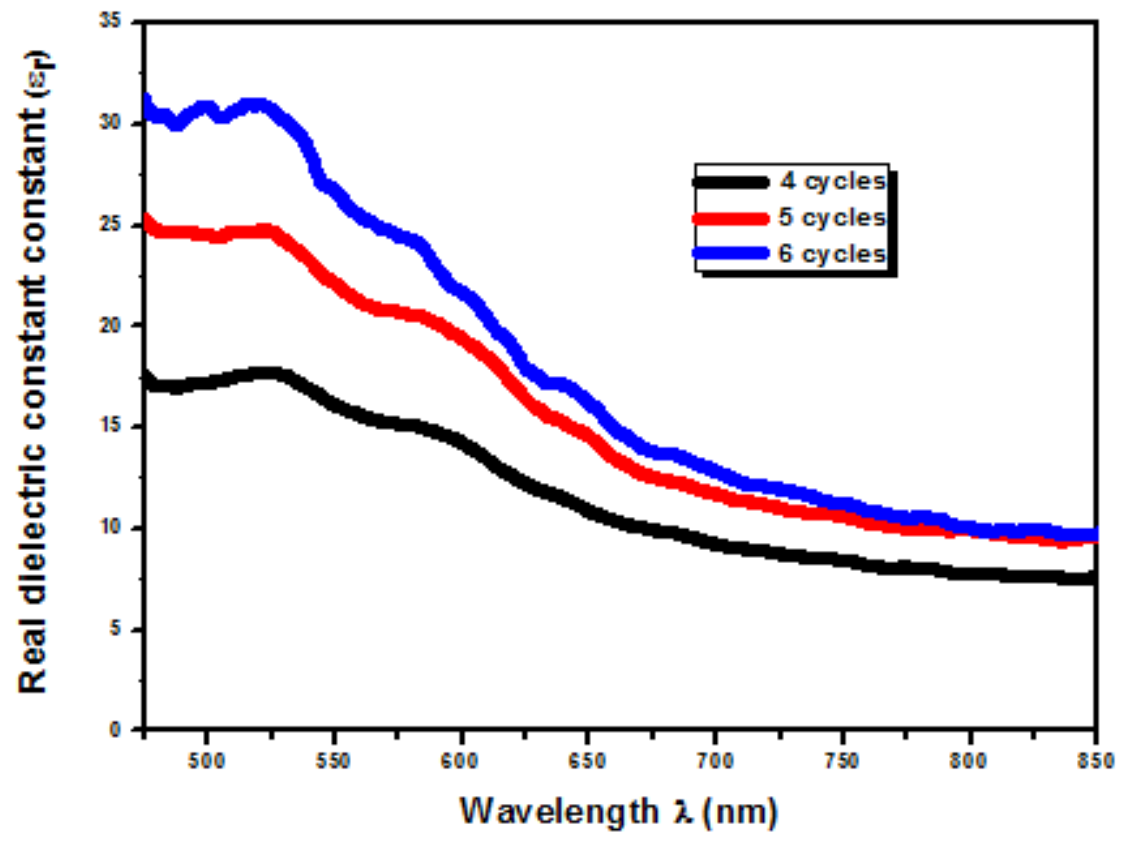

Figure 11

Real dielectric constant of quaternary CNTS thin films 


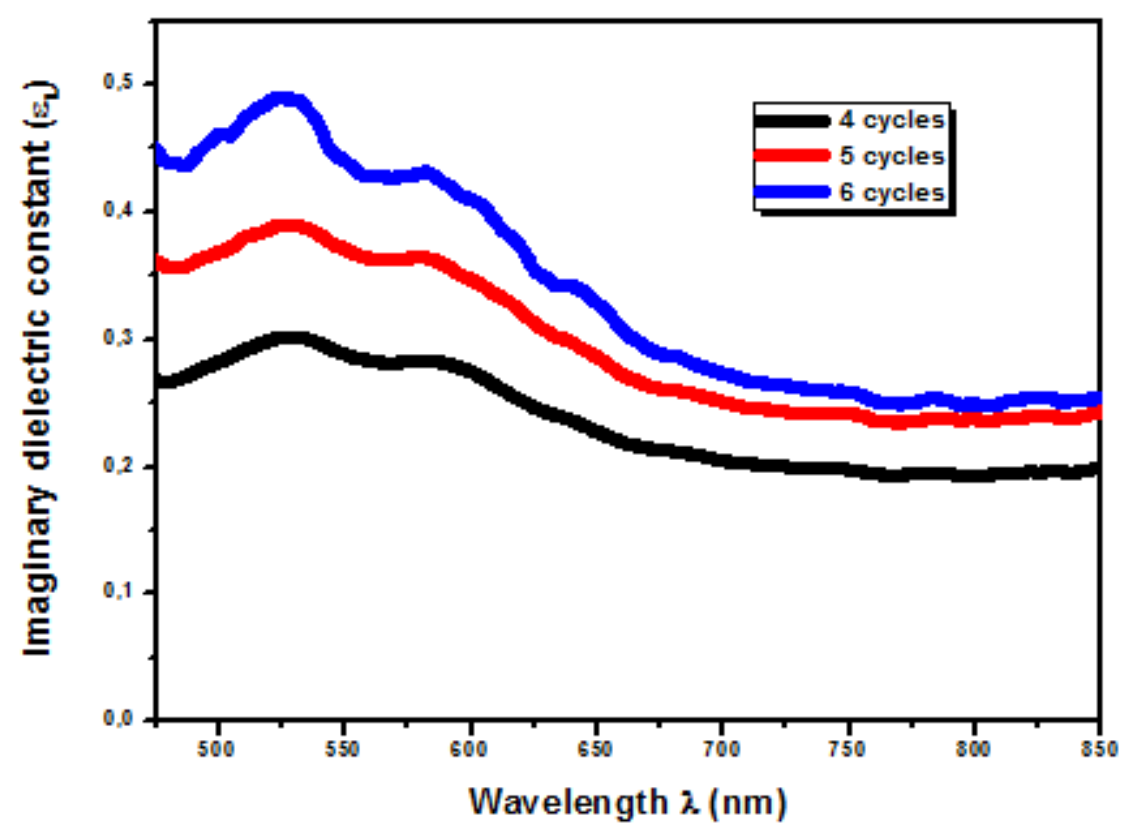

Figure 12

Imaginary dielectric constant of deposited CNTS thin films

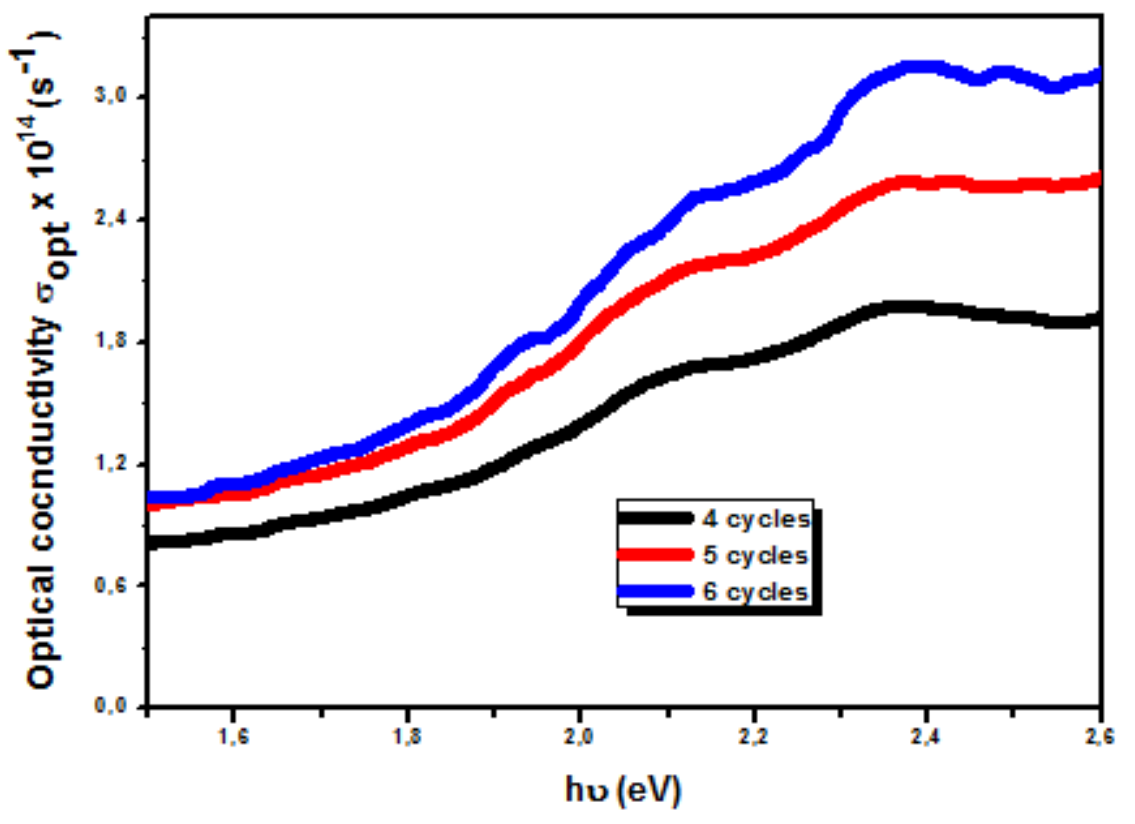

Figure 13

optical conductivity versus photon energy hv of dip-coated CNTS thin films 